\title{
Projection of Landfalling-Tropical Cyclone Rainfall in the Eastern United States under Anthropogenic Warming
}

\author{
MAOFENG LIU \\ Department of Civil and Environmental Engineering, Princeton University, Princeton, New Jersey \\ GABRIEL A. VECCHI \\ Department of Geosciences, and Princeton Environmental Institute, Princeton University, Princeton, New Jersey \\ JAMES A. SMITH \\ Department of Civil and Environmental Engineering, Princeton University, Princeton, New Jersey \\ HIROYUKI MURAKAMI \\ NOAA/Geophysical Fluid Dynamics Laboratory, and Atmospheric and Oceanic Sciences Program, \\ Princeton University, Princeton, New Jersey
}

(Manuscript received 1 November 2017, in final form 24 April 2018)

\begin{abstract}
Landfalling-tropical cyclone (TC) rainfall is an important element of inland flood hazards in the eastern United States. The projection of landfalling-TC rainfall under anthropogenic warming provides insight into future flood risks. This study examines the frequency of landfalling TCs and associated rainfall using the GFDL Forecast-Oriented Low Ocean Resolution (FLOR) climate model through comparisons with observed TC track and rainfall over the July-November 1979-2005 seasons. The projection of landfalling-TC frequency and rainfall under the representative concentration pathway (RCP) 4.5 scenario for the late twentyfirst century is explored, including an assessment of the impacts of extratropical transition (ET). In most regions of the southeastern United States, competition between increased storm rain rate and decreased storm frequency dominates the change of annual TC rainfall, and rainfall from ET and non-ET storms. In the northeastern United States, a prominent feature is the striking increase of ET-storm frequency but with tropical characteristics (i.e., prior to the ET phase), a key element of increased rainfall. The storm-centered rainfall composite analyses show the greatest increase at a radius of a few hundred kilometers from the storm centers. Over both ocean and land, the increase of rainfall within $500 \mathrm{~km}$ from the storm center exceeds the Clausius-Clapeyron scaling for TC-phase storms. Similar results are found in the front-left quadrant of ET-phase storms. Future work involving explorations of multiple models (e.g., higher atmospheric resolution version of the FLOR model) for TC-rainfall projection is expected to add more robustness to projection results.
\end{abstract}

\section{Introduction}

Rainfall associated with landfalling tropical cyclones (TCs) is responsible for fatalities and significant economic and societal losses in the United States (Rappaport 2000; Czajkowski et al. 2011; Willoughby 2012; Chavas et al. 2013; Czajkowski et al. 2013; Rappaport 2014). TC rainfall and associated flooding can affect large areas, with impacts extending a few hundred kilometers from the storm center (e.g., Atallah and Bosart 2003; Colle 2003;

Corresponding author: Maofeng Liu, maofeng@princeton.edu
Lin et al. 2010; Villarini et al. 2011; Chen et al. 2014; Liu and Smith 2016).

Previous studies have demonstrated the central role of TCs in determining the upper tail of flood peak distributions in the eastern United States (Smith et al. 2011; Villarini and Smith 2010) and rainfall extremes across the global tropics (Khouakhi et al. 2017). The changing character of TC rainfall is of significant concern to both coastal and inland areas. An observational study found that the 1994-2008 TC-related heavy rain events doubled a long-term average in the United States (Kunkel et al. 2010). The prediction and projection of 
the time trend of landfalling-TC rainfall have important implications for flood risk management.

Knutson et al. (2010) reviewed studies using a range of climate models and warming scenarios and found that none reported decreases of TC rainfall. The regional climate model studies through dynamical downscaling of outputs from a range of climate models found that the precipitation rate within $100 \mathrm{~km}$ of the storm center is projected to increase on the order of $20 \%$ for the late twenty-first century in the North Atlantic, surpassing the Clausius-Clapeyron scaling relationship (Knutson et al. 2008, 2013). Knutson et al. (2015) extended the work in Knutson et al. (2013) to the global scale using a similar downscaling framework but with different model settings. They reported increased TC rainfall in terms of global average, while this increase varies across basins. For the North Atlantic, although Knutson et al. (2015) did find an increase in TC rainfall in twenty-first-century projections, it was not as pronounced an increase as that reported in Knutson et al. (2013).

Villarini et al. (2014a) conducted a study on the global projection of TC rainfall with three global atmospheric climate models and found globally increased TC rainfall on the order of $10 \%-20 \%$ under warming scenarios involving SST increase and $\mathrm{CO}_{2}$ doubling, arising from an SST-induced increase and a partially compensating $\mathrm{CO}_{2}$-induced reduction in TC rainfall. A study by Scoccimarro et al. (2014) that focused on landfalling TCs in the same model experiments as Villarini et al. (2014a) also reported increased landfalling-TC rainfall. Wright et al. (2015) adopted the dynamical downscaling framework introduced in Knutson et al. (2013) for examining the response of landfalling-TC rainfall in the eastern United States to global warming. They found increased rainfall for individual TCs over both ocean and land. The projected changes of landfalling-TC rainfall show different geographic distributions for varied warming scenarios. The modeling domain limits the model from simulating TCs in the northeastern United States where TCs play a significant role in extreme rain events (e.g., Barlow 2011).

Extratropical transition (ET), as illustrated by Hurricane Agnes (1972) (DiMego and Bosart 1982), Hurricane Floyd (1999) (Atallah and Bosart 2003; Colle 2003), and Hurricane Irene (2011) (Liu and Smith 2016), is a central feature of extreme rainfall from TCs in the northeastern United States. There are few studies on the role of ET in the change of TC rainfall under global warming. A recently developed Geophysical Fluid Dynamics Laboratory (GFDL) global coupled model, the Forecast-Oriented Low Ocean Resolution (FLOR) model (Vecchi et al. 2014; Jia et al. 2015) shows good skill in simulating various aspects of ET climatology (Liu et al. 2017), and thus provides a promising tool for examining the impacts of extratropical transition on TC rainfall.

We aim to understand the responses of landfalling-TC rainfall to projected anthropogenic warming using the FLOR coupled climate model. We evaluate the skill of the model in simulating the present climatology of landfalling-TC frequency and associated rainfall. Specifically, we explore the role of ET in the responses of landfalling-TC activity to anthropogenic warming. We organize this study as follows. Data and methods are presented in section 2, followed by results in section 3 . A summary is given in section 4 .

\section{Data and methods}

\section{a. Dynamical model}

We use the FLOR configuration of the GFDL Climate Model, version 2.5 (CM2.5; Delworth et al. 2012). The atmosphere and land components of the FLOR model are obtained from CM2.5 with a spatial grid resolution of approximately $50 \mathrm{~km} \times 50 \mathrm{~km}$. The ocean component is from CM2.1 with a spatial grid resolution of approximately $1^{\circ} \times 1^{\circ}$ (Delworth et al. 2006). A detailed description of the FLOR model (hereinafter FLOR) can be found in Vecchi et al. (2014). We use a flux-adjusted version of FLOR in which biases of the momentum, enthalpy, and freshwater fluxes from the atmosphere to the ocean are adjusted so that the climatological SST and surface wind stress become closer to observations (Vecchi et al. 2014). The flux adjustment improves the skill of FLOR in simulating and predicting regional TC activity (Vecchi et al. 2014) and simulating ET activity (Liu et al. 2017). In addition, FLOR with flux adjustment exhibits skill in seasonal forecasts of landfalling TCs in the North Atlantic (Murakami et al. 2016a) and the western North Pacific (Zhang et al. 2016a, 2017).

Historical simulations were run over 1861-2005 with prescribed forcing from phase 5 of the Coupled Model Intercomparison Project (CMIP5) historical forcing scenario for greenhouse gas concentration, aerosols, ozone, and volcanic events. For the simulations beyond 2005, the model was run using the 2006-2100 CMIP5 representative concentration pathway 4.5 (RCP4.5) scenario forcings, which represent a "mid-range scenario" for greenhouse gas concentrations. We examine the skill of FLOR in simulating the statistics of landfallingTC frequency and rainfall through the comparison between FLOR results and observations over the period 1979-2005. The change of landfalling-TC frequency and rainfall is explored by examining the climatological 
difference between two periods: the global warming (GW) run over 2056-2100 and the present-day (PD) run over 1961-2005. For each year, we focus on the core hurricane season (i.e., July-November). To achieve more robust results, we use five ensembles of FLOR with varied initial conditions.

We use the tracking scheme developed in Harris et al. (2016), as implemented in Murakami et al. (2015) to detect FLOR-generated TCs from 6-hourly model outputs. This scheme uses a flood fill algorithm to find closed pressure contours around each sea level pressure (SLP) low center. Within the contours, it uses the 300 $500-\mathrm{hPa}$ air temperature anomaly to determine the warm-core characteristic of the negative SLP anomaly. For each detected TC, the scheme also requires 1) a duration of at least $72 \mathrm{~h}$ and 2) consecutive $36 \mathrm{~h}$ of warmcore characteristic, as well as maximum $10-\mathrm{m}$ wind stronger than $17.5 \mathrm{~m} \mathrm{~s}^{-1}$. More details of the tracking scheme can be found in Murakami et al. (2015).

We use "track density" to represent the regional TC activity. For each $1^{\circ}$ grid cell, the track density is defined as the total number of days in a season for which the storm centers of TCs are within $500 \mathrm{~km}$ of the grid (Vecchi et al. 2014). The criterion for 500-km storm size is consistent with observational studies (e.g., Chavas and Emanuel 2010) and has been widely used in TC studies examining extratropical transition (Evans and Hart 2003; Hart 2003), rainfall (e.g., Jiang and Zipser 2010; Barlow 2011; Prat and Nelson 2013; Wright et al. 2013, 2015; Khouakhi et al. 2017), and flooding (e.g., Smith et al. 2011; Villarini and Smith 2010; Villarini et al 2014b; Wright et al. 2014).

\section{b. Data}

We obtain tropical cyclone tracks from the National Hurricane Center's hurricane best track database (HURDAT2; Landsea and Franklin 2013) for the period 1979-2005. The database provides 6-hourly "best track" data for observed TCs in the North Atlantic. To be consistent with the tracker in FLOR, we use observed storms with at least tropical storm intensity (i.e., wind speed $\geq 17.5 \mathrm{~m} \mathrm{~s}^{-1}$ ) as well as 3-day duration. We obtain observed rainfall data for evaluating FLOR-simulated TC rainfall from the North American Land Data Assimilation System (NLDAS; Mitchell et al. 2004), which provides hourly, $1 / 8^{\circ}$-gridded rainfall fields over the continental United States. In NLDAS, the Climate Prediction Center gauge-based daily rainfall is temporally disaggregated to hourly scale using information from multiple sources for rainfall, including radar, satellite, gauge, and reanalysis data. To facilitate comparison, the $1 / 8^{\circ}$ rainfall from NLDAS is resampled to the same spatial resolution as FLOR-simulated rainfall. The reanalysis dataset used for discriminating ET and nonET storms is the 6-hourly, $0.5^{\circ}$-resolution National Centers for Environmental Prediction (NCEP) Climate Forecast System Reanalysis (CFSR; Saha et al. 2010).

\section{c. Cyclone phase space}

The cyclone phase space (CPS) method is used to determine the occurrence of extratropical transition (Evans and Hart 2003; Hart 2003). This method has been widely used in ET climatology studies across basins including the North Atlantic (Evans and Hart 2003), western North Pacific (Kitabatake 2011), and eastern North Pacific (Wood and Ritchie 2014). CPS uses 900$600-\mathrm{hPa}$ thermal thickness asymmetry $B, 900-600-\mathrm{hPa}$ thermal wind $-V_{T}^{L}$, and $600-300-\mathrm{hPa}$ thermal wind $-V_{T}^{U}$ to characterize the thermal evolution of a storm. A detailed description of the three parameters can be found in Evans and Hart (2003) and Hart (2003). Following Liu et al. (2017), the onset of extratropical transition is triggered when $B$ is larger than $10 \mathrm{~m}$ or $-V_{T}^{L}$ is lower than 0 . The completion of extratropical transition is determined when the two conditions are both satisfied.

We implement CPS in CFSR data to determine the ET characteristics of storms observed in HURDAT2 data. It is worth noting that HURDAT2 also provides the timing at which the storm changes into an extratropical cyclone (McAdie et al. 2009). The agreement between CPS and HURDAT2 for ET detection reaches $79.1 \%$. In addition, ET- and non-ET-storm rainfall from the two methods show relatively small differences (figure not shown). HURDAT2 is excluded from detecting ET storms because it does not allow rainfall analyses associated with ET processes because of the lack of timings on ET onsets. We also test the robustness of CPS in detecting ET events by varying the empirical threshold for thickness asymmetry. The change of the threshold from 8 to $12 \mathrm{~m}$ leads to a small variation of ET rate (within $2.5 \%$ ).

\section{d. Rainfall attribution}

The change of landfalling-TC rainfall under greenhouse warming can be directly attributed to two factors: the storm rain rate and storm frequency. We use a simple analysis to identify the respective contribution from each. For each cell, the annual (i.e., JulyNovember) storm rainfall is computed as $P=R \times F$, where $P$ is the storm rainfall, $R$ is the average annual rain rate for all storms, and $F$ is the annual storm frequency. We obtain the change of the total storm rainfall as $P^{\prime}=R^{\prime} F+R F^{\prime}+R^{\prime} F^{\prime}$, where $P^{\prime}$ is the change of storm total rainfall, $R^{\prime}$ is the change of storm rain rate, and $F^{\prime}$ is the change of storm frequency. The first and second terms are contributions from storm rain rate and 

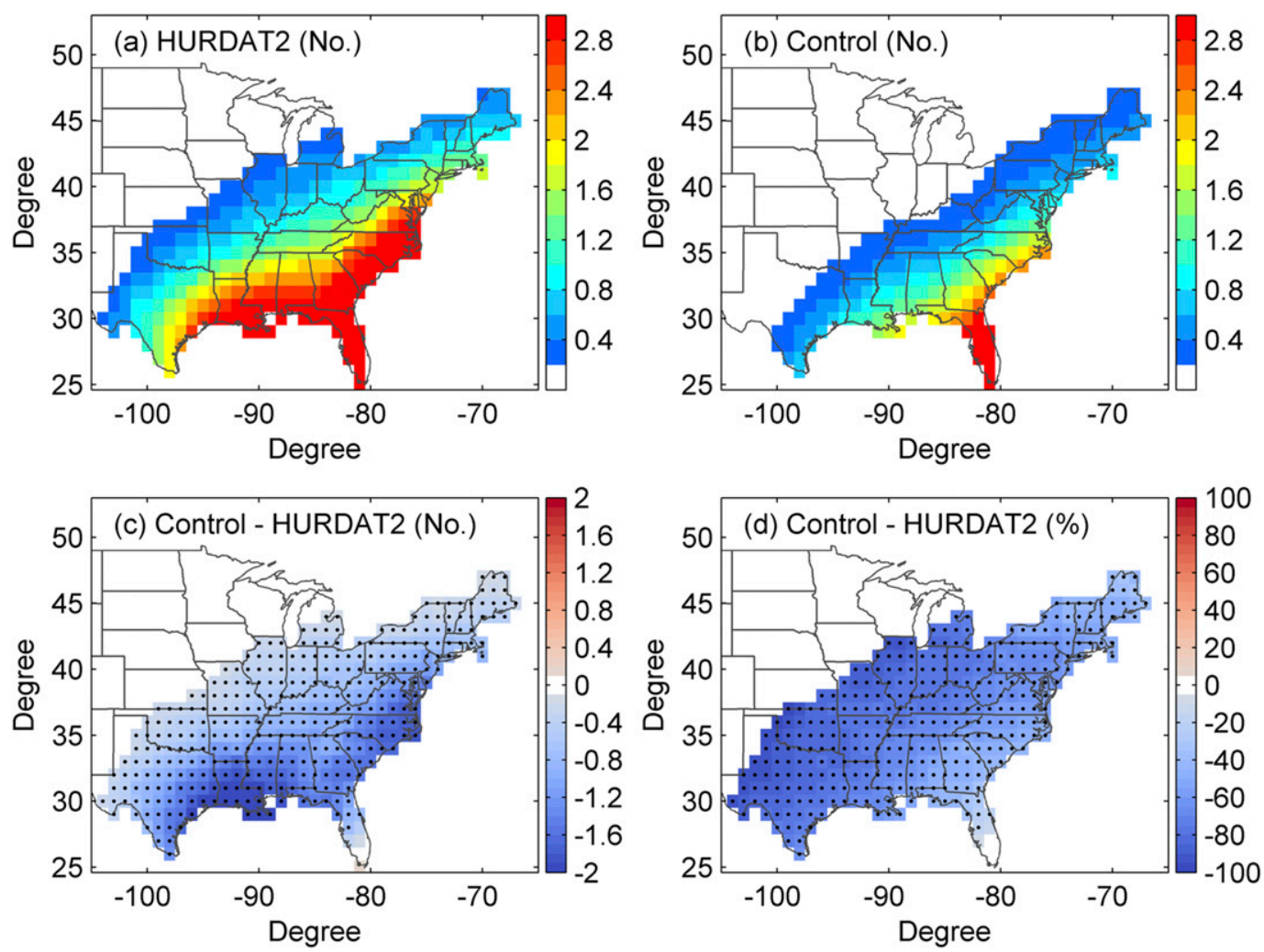

FIG. 1. July-November landfalling-TC density (TC days) from (a) HURDAT2, (b) FLOR control simulations, and (c),(d) TC density difference between the FLOR control simulation and HURDAT2 in the United States. Black dots indicate statistical significance $(p<0.1)$ based on the two-sided two-sample Student's $t$ test, the same as later figures. Regions with TC density lower than 0.2 TC days are masked.

storm frequency, respectively, given that the other factor maintains unchanged. The third term $R^{\prime} F^{\prime}$ is the covariance effect. We find that it has a much lower magnitude than the first two terms, so it is not included in the following analyses.

\section{Results}

\section{a. Simulation of landfalling-TC density and associated rainfall}

We first compare the July-November 1979-2005 U.S. TC frequency from HURDAT2 and FLOR simulations (Fig. 1). The observed landfalling-storm frequency gradually decreases as one moves northwestward from Florida (Fig. 1a). This geographic pattern is well simulated by FLOR (Fig. 1b). FLOR underestimates the TC density by approximately $20 \%$ along the U.S. East Coast. This negative bias becomes greater as one moves farther inland (Figs. 1c,d). Similarly, a previous study that used the downscaling approach simulated lower TC density than observations in most eastern coastal states (Wright et al. 2015; their Fig. 1). The negative bias of TC density from FLOR compared to HURDAT2 has two peaks, one in the northern states of the Gulf of Mexico and the other in Georgia and the Carolinas (Fig. 1c), which may be partly due to underestimated TC-genesis frequency (not shown; Vecchi et al. 2014; Murakami et al. 2016a).

The ability of the model to simulate larger-scale climate conditions is important to the simulation of landfall-TC activity (Lyons 2004). FLOR shows good skill in capturing the impact of El Niño-Southern Oscillation (ENSO) on TC landfall (Murakami et al. 2016a). FLOR does not, however, accurately simulate the correlation between the summer North Atlantic Oscillation (SNAO) and the landfall ratio (Murakami et al. 2016a), which may be another factor that weakens the performance of FLOR in simulating landfalling-TC density.

Similar to the TC-frequency analyses, we examine landfalling-TC rainfall through comparisons between FLOR simulations and NLDAS for the July-November 1979-2005 seasons (Fig. 2). Following the criterion used for TC density, only rainfall within $500 \mathrm{~km}$ from the storm center is considered as TC-related rainfall. 

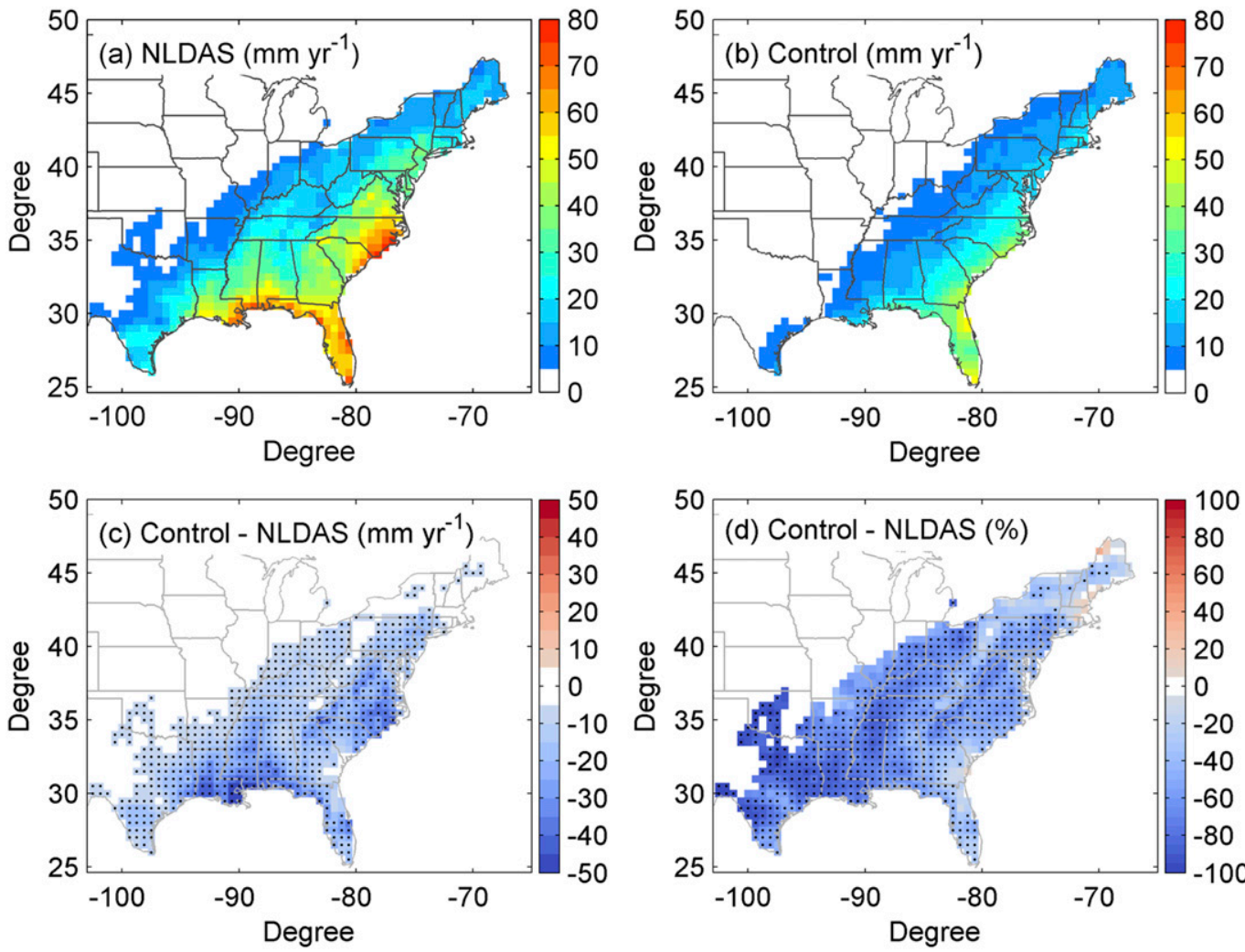

FIG. 2. July-November landfalling-TC rainfall from (a) NLDAS, (b) FLOR control simulations, and (c),(d) TC rainfall difference between the FLOR control simulations and NLDAS in the United States. Regions with storm rainfall lower than $5 \mathrm{~mm} \mathrm{yr}^{-1}$ are masked.

The observed rainfall from NLDAS exhibits pronounced spatial heterogeneity (Fig. 2a). We see sharp spatial contrast of rainfall along the eastern margin of the central Appalachian Mountains, and orographic mechanisms are key elements in contributing to this geographic distribution of TC rainfall. FLOR captures this feature but underestimates the rainfall magnitude. On the western side of the central Appalachian Mountains, the local rainfall minimum in Tennessee and Kentucky is likely due to the leeside effect of terrain, as also seen in flood (Villarini and Smith 2010) and gauge rainfall analyses (Hart and Evans 2001). In contrast, we observe a regional rainfall maximum in western North Carolina and Virginia, likely due to orographic enhancement (SturdevantRees et al. 2001).

Despite missing some spatial details, FLOR-generated rainfall generally reflects the geographic distribution of rainfall from NLDAS (Fig. 2). Because the storm rain rate produced by FLOR is comparable to that from NLDAS (as discussed below), the negative bias of TC rainfall by FLOR is largely attributable to the underestimation of landfalling-TC density (Fig. 1).

To explore the role of ET in the rainfall distribution of landfalling TCs, we compute the July-November rainfall for ET and non-ET storms, respectively. Despite the underestimation of rain rate, FLOR shows skill in simulating the spatial pattern of rainfall fields from the two types of events (Fig. 3). ET and non-ET storms produce striking spatial contrasts of rainfall accumulations. As seen in both NLDAS and FLOR, ET-storm rainfall stretches northward to Maine while non-ETstorm rainfall is constrained to relatively low latitudes. ET storms dominate the TC rainfall along the east coast of the United States (Figs. 3a,c). The non-ET-storm rainfall is concentrated from Texas to Florida along the coastal line of the Gulf of Mexico, in agreement with low ET rate from TCs passing the Gulf of Mexico (Figs. 3b,d; Liu et al. 2017). FLOR underestimates the non-ET rainfall in Texas and Louisiana, probably as a result of lower simulated TC density than in observations.

To further assess the role of ET in landfalling-storm rainfall, we use the CPS method to break each ET storm into a TC phase and an ET/extratropical (EX) phase. For each storm, the TC phase is referred to as the stage in which the storm maintains a symmetric warm-core structure. The time since the onset of ET is referred to as the ET/EX phase. The storm rainfall for the two phases is computed over the July-November 1979-2005 seasons, respectively. 

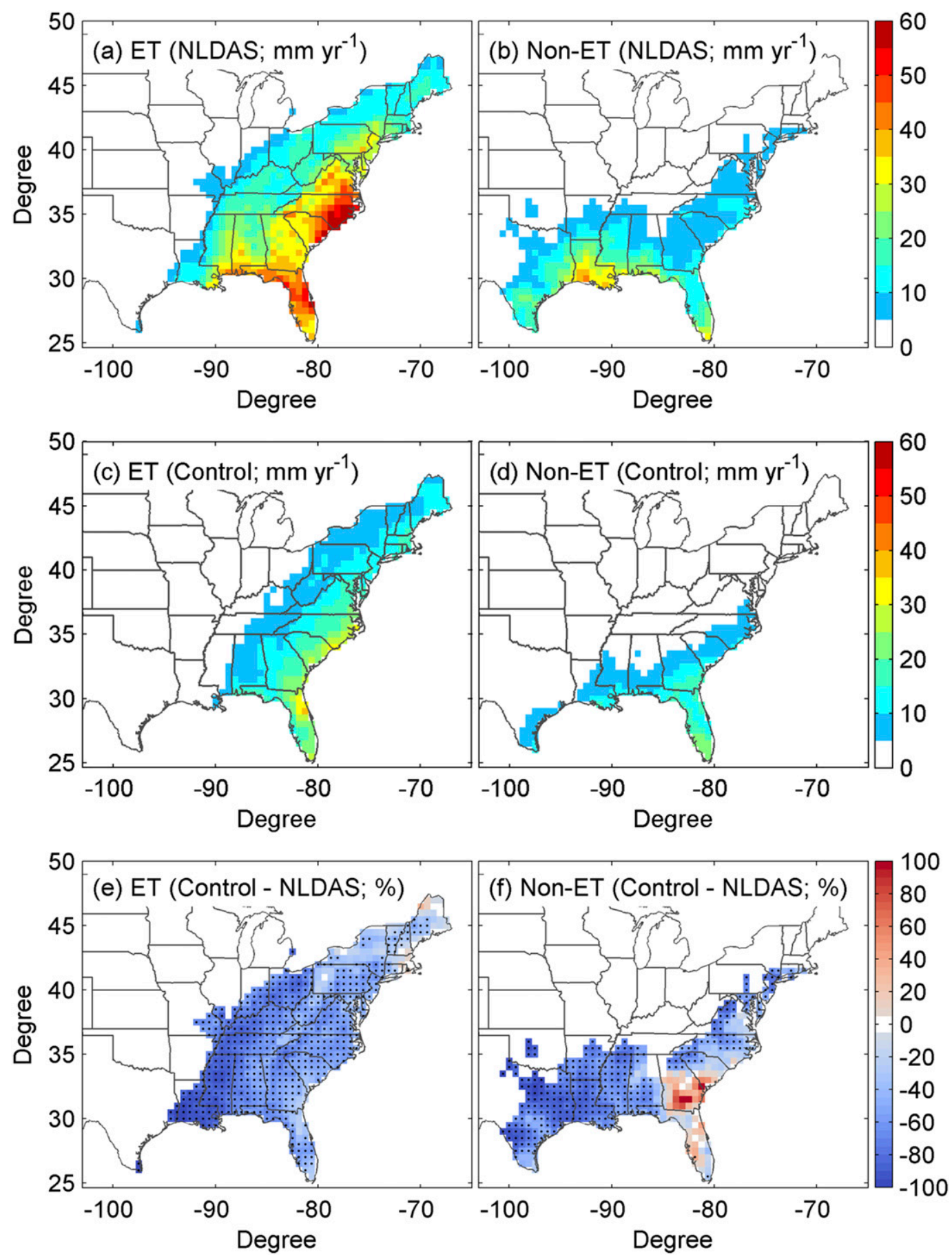

FIG. 3. July-November landfalling-ET-storm rainfall from (a) NLDAS, (c) FLOR control simulations, and (e) storm rainfall difference between the FLOR control simulations and NLDAS. (b),(d),(f) As in (a),(c),(e), but for non-ET-storm rainfall. Regions with storm rainfall lower than $5 \mathrm{~mm} \mathrm{yr}^{-1}$ are masked.

Through the comparisons with rainfall observations in NLDAS, FLOR shows good skill in simulating the spatial contrast of rainfall from the two phases (Fig. 4). In the southeastern United States, the TC phase plays a dominant role in ET-storm rainfall accumulations compared to the
ET/EX phase (Fig. 4). The impact of the TC phase in the storm rainfall, however, is constrained below about $40^{\circ} \mathrm{N}$ (Figs. 4a,c). There is no such constraint for the ET/EX phase. For both NLDAS and FLOR (Figs. 4b,d), the ET/EX phase dominates the TC rainfall in the 

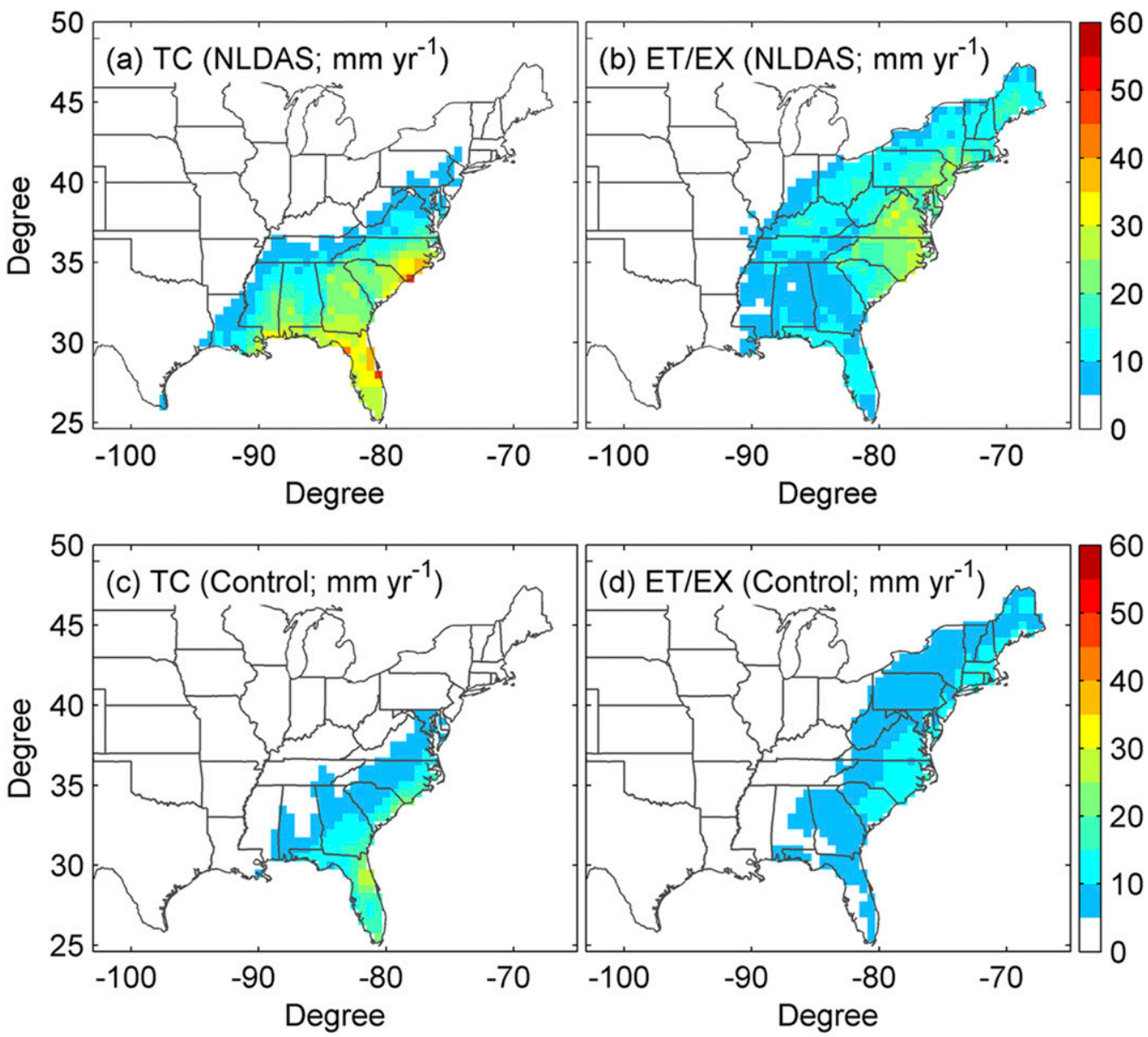

(d) ET/EX (Control; $\mathrm{mm} \mathrm{yr}^{-1}$ )
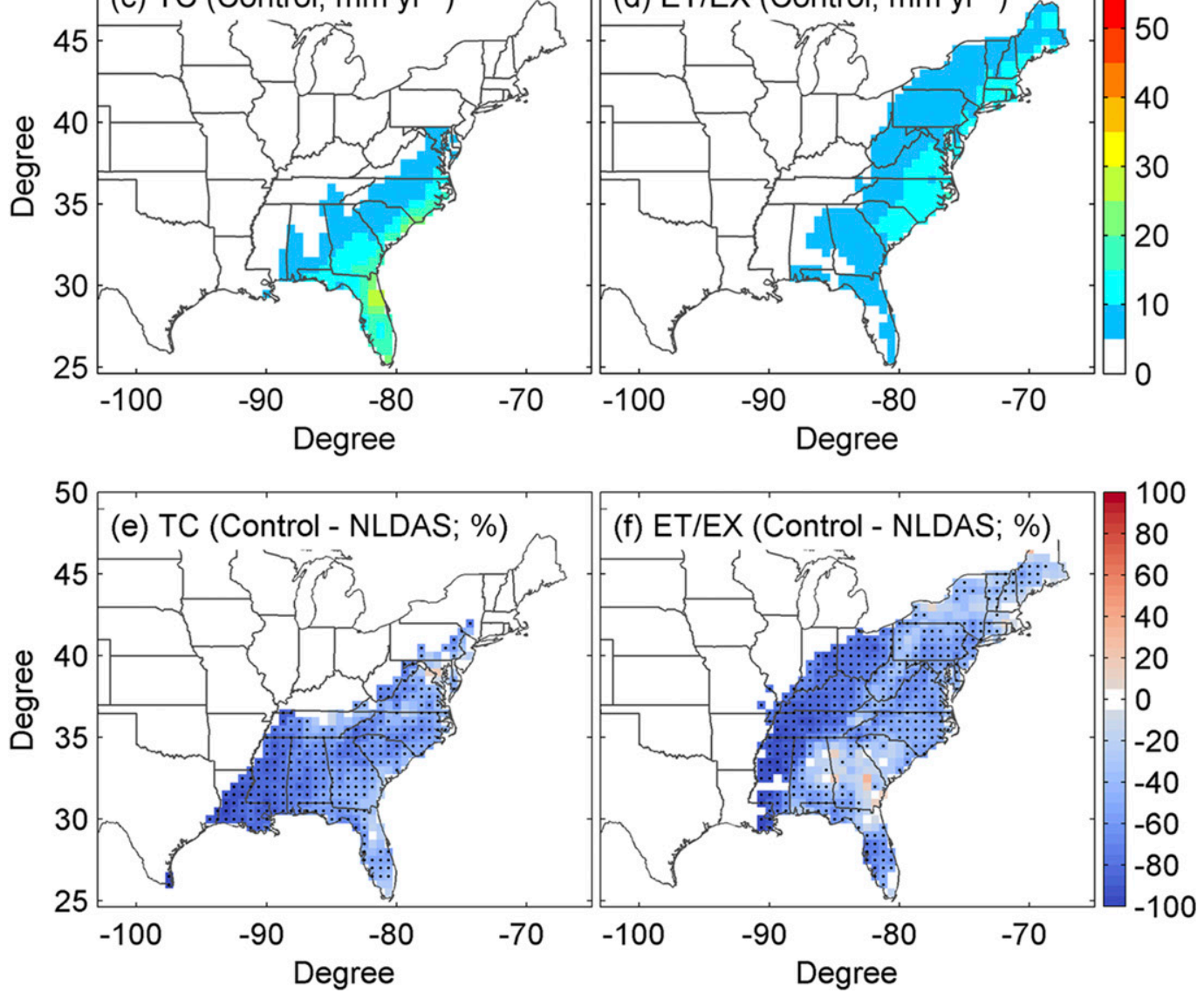

FIG. 4. July-November TC-phase rainfall from (a) NLDAS and (b) FLOR control simulations, and JulyNovember ET/EX-phase rainfall from (c) NLDAS and (d) FLOR control simulations. Rainfall difference between the FLOR control simulations and NLDAS for the (e) TC phase and (f) ET/EX phase. Regions with storm rainfall lower than $5 \mathrm{~mm} \mathrm{yr}^{-1}$ are masked.

northeastern United States (e.g., New England) (Fig. 4). In addition, storms in the ET/EX phase can interact with the Appalachian Mountains to produce mixed rainfallgenerating mechanisms in the northeastern United States, highlighting extreme rainfall and associated flood risks (Hart and Evans 2001; Atallah and Bosart 2003; Colle 2003; Smith et al. 2011; Villarini and Smith 2010; Liu and Smith 2016). 
(a) TC (NLDAS; mm day ${ }^{-1}$ )

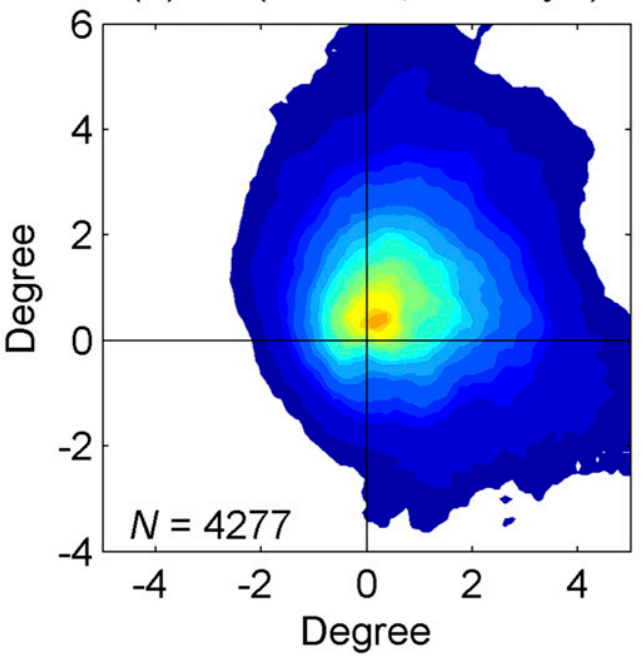

(c) TC (Control; $\mathrm{mm}_{\text {day }}{ }^{-1}$ )

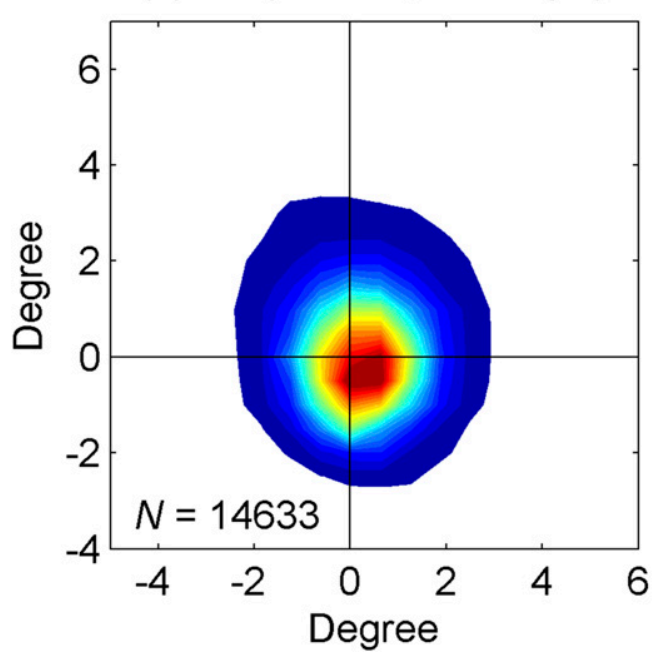

(b) ET/EX (NLDAS; mm day ${ }^{-1}$ )

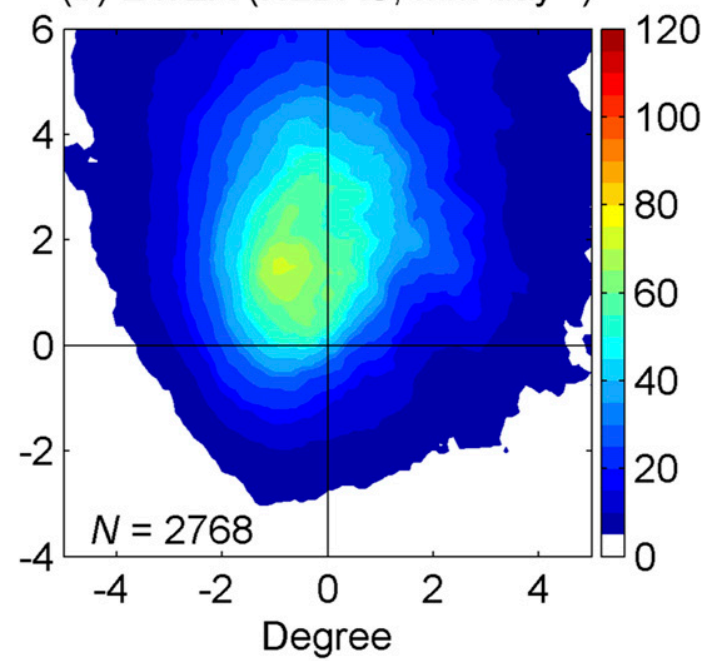

(d) ET/EX (Control; mm day ${ }^{-1}$ )

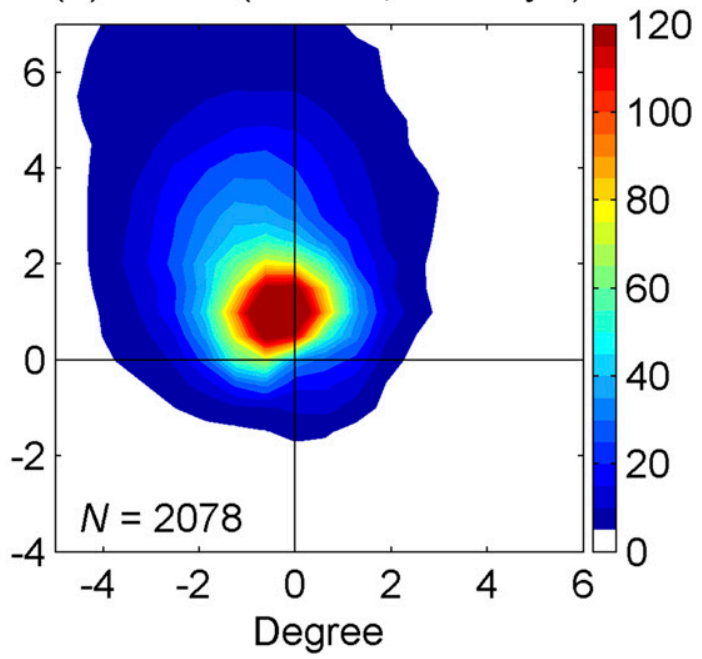

FIG. 5. Average storm-centered rainfall composite $\left(\mathrm{mm} \mathrm{day}^{-1}\right.$ ) for (a),(b) NLDAS and (c),(d) FLOR simulations for the (a),(c) TC phase and (b),(d) ET/EX phase over land. Non-ET storms are included in the TC phase because of their similar nature. The positive $y$ axis points in the direction of TC motion, and $N$ indicates the number of storm samples used. Regions with storm rainfall lower than $5 \mathrm{~mm}$ day $^{-1}$ are masked.

We compute the average storm-centered landfallingTC rainfall composite during the July-November 19792005 seasons for the TC and ET/EX phases, respectively (Fig. 5). Before translating each rainfall field to the origin for the composite, we rotate it so that the storm motion has the same direction as the positive $y$ axis. The non-ET-storm rainfall is included in the TC-phase analysis because of its symmetric warm-core nature. The TC-phase rainfall observed from NLDAS is concentrated in the front quadrants, highlighting the effect of land-sea contrasts (Fig. 5a). Although in FLOR simulations we observe a larger concentration of rainfall in the front quadrants in landfalling TCs than storms over ocean (not shown), this feature is more clearly seen from NLDAS. This may be due to the inadequate horizontal resolution of land surfaces used in FLOR.

FLOR produces higher inner-core rain rates than NLDAS, which may result from several factors. Villarini et al. (2011) found that NLDAS underestimates the rainfall intensity of TCs compared to the stage IV precipitation analysis, a multisensor rainfall dataset produced by National Weather Service (NWS) River Forecast Centers (RFCs) over the continental United States (Lin and Mitchell 2005). In addition, there is a sampling difference between the hourly rainfall from NLDAS and the instantaneous rainfall from FLOR, and the former may 

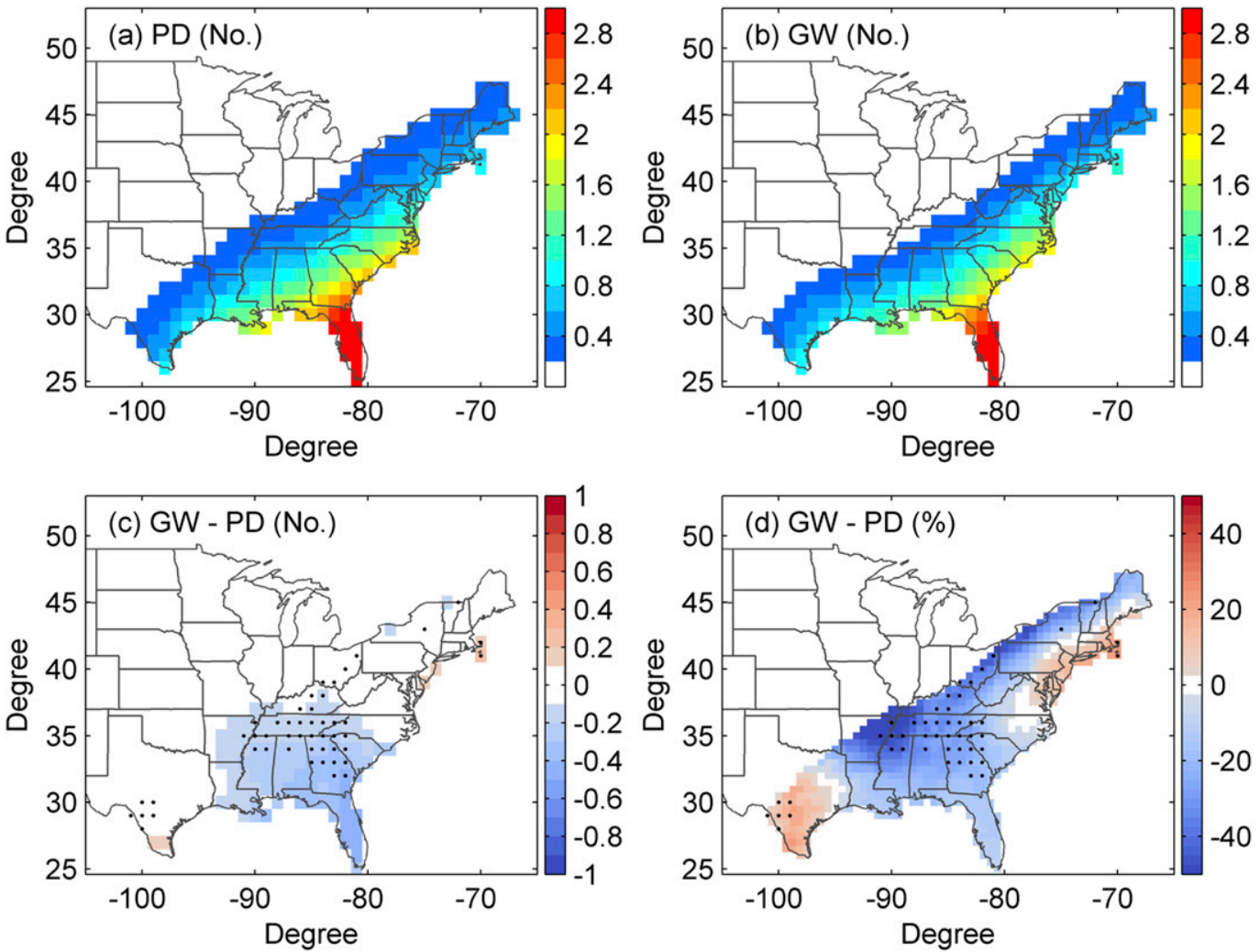

FIG. 6. July-November landfalling-TC density (TC days) from the (a) PD simulation, (b) GW projection, and (c),(d) TC density difference between the GW and PD runs. Regions with TC density lower than 0.2 TC days are masked.

provide lower rainfall magnitudes as a result of temporal averaging. A third contributing factor is that FLOR simulates higher rain rates near the eyewall and lower rain rates far from the storm center, compared with NLDAS. This implies that water vapor convergence in FLOR tends to be consumed as eyewall convection rather than in rainbands. As shown in both NLDAS and FLOR (Figs. 5b,d), the rainfall for the ET/EX phase is concentrated in the front-left quadrant relative to the storm center, consistent with previous studies (Atallah and Bosart 2003; Colle 2003; Atallah et al. 2007; Liu and Smith 2016; Liu et al. 2017). The rainfall for the ET/EX phase impacts larger areas than the TC phase, implying enhanced rainfall accumulations and associated flood risks.

\section{b. Projection of landfalling-TC density and associated rainfall}

We first examine the change of July-November landfalling-TC frequency through the climatological difference between the GW and PD runs (Fig. 6). FLOR projects approximately a $10 \%-20 \%$ decrease of TC density in the southeastern United States, partly as a result of decreased TC genesis in the western portion of the North Atlantic (Liu et al. 2017). However, Wright et al. (2015) found a less pronounced decrease of TC frequency in these regions. FLOR projects approximately a $10 \%-20 \%$ increase of TC density around the northeast coast of the United States, broadly in agreement with previous studies (Wright et al. 2015). Increased TC genesis in the eastern portion of the North Atlantic is an important element of this TC density increase (Liu et al. 2017).

In addition to the changing property of storm frequency, we examine the change of the July-November U.S. TC rainfall under the RCP4.5 scenario (Fig. 7). We use a simple analysis to attribute the change of TC rainfall to two drivers: storm frequency and rain rate (Figs. 7e,f). In much of the southeastern United States, the competition between increased storm rain rate and decreased storm frequency leads to heterogeneous patterns of changing TC rainfall (Figs. 7c-f). The change is statistically significant in few regions although larger regions with significant change are found for both storm rain rate and storm frequency. Broadly in agreement with results reported in Wright et al. (2015), FLOR projects increased rainfall in the 

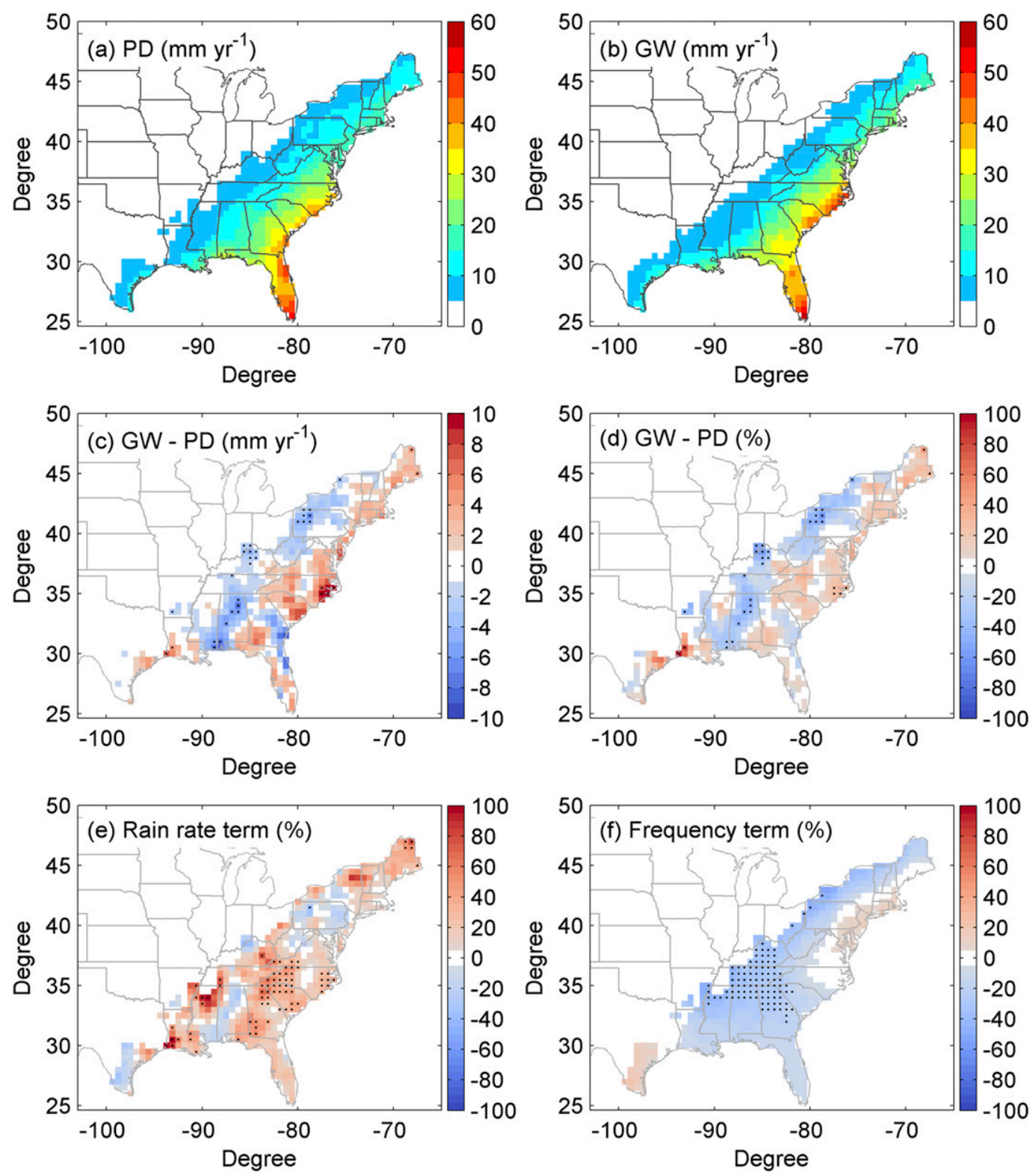

FIG. 7. July-November landfalling-TC rainfall from the (a) PD and (b) GW runs, and (c),(d) projected change in TC rainfall between the GW and PD runs. (e) The contribution of the storm rain-rate term and (f) the frequency term to the change of TC rainfall. Regions with storm rainfall lower than $5 \mathrm{~mm} \mathrm{yr}^{-1}$ are masked.

Carolinas and Virginia and decreased rainfall in southeastern Georgia. In the northeastern United States, the rain-rate term exhibits more heterogeneous geographic distribution than that in the southeastern United States (Fig. 7e). The contribution of the storm frequency term to TC rainfall gradually shifts from positive to negative from the coast to inland (Fig. 7f).

We examine the role of ET in the July-November TCrainfall projection by dividing all TCs into ET and non-ET storms using the CPS analysis (Fig. 8). The change of
ET-storm rainfall generally resembles that of TC rainfall in the eastern coastal states (Figs. 7 and 8). In the southeastern United States, the geographic distribution of the change of ET-storm rainfall is determined by increased storm rain rate and decreased storm frequency (Figs. 8c,e), similar to the change of TC rainfall (Figs. 7e,f). In spite of a significant increase of storm rain rate in the southern Appalachian Mountain regions, the rainfall increase is not significant because of decreased storm frequency. An exception is that the significant decrease of ET-storm rainfall in Alabama can be attributable to both decreased storm frequency and 

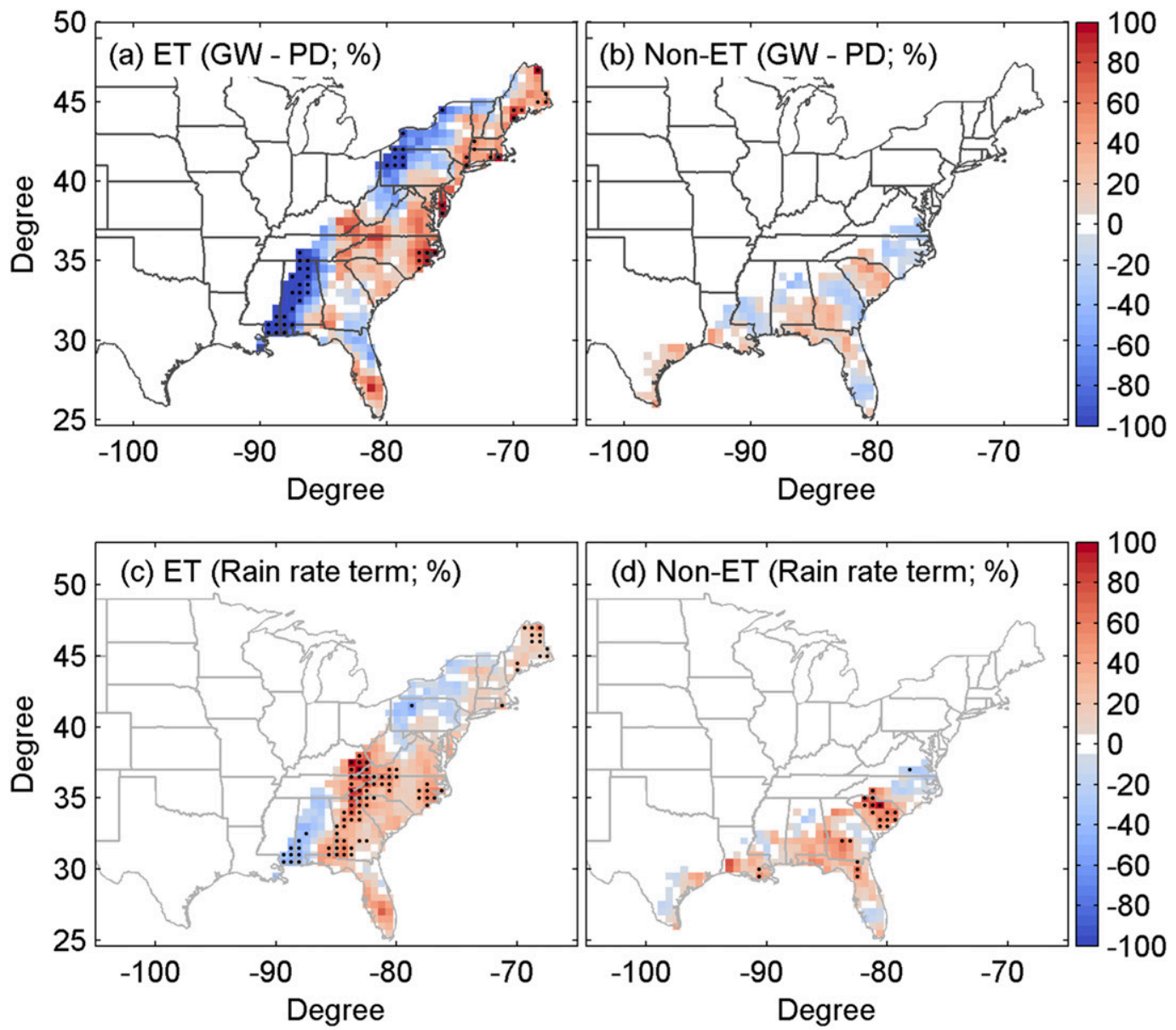

(d) Non-ET (Rain rate term; \%)

100

80

60
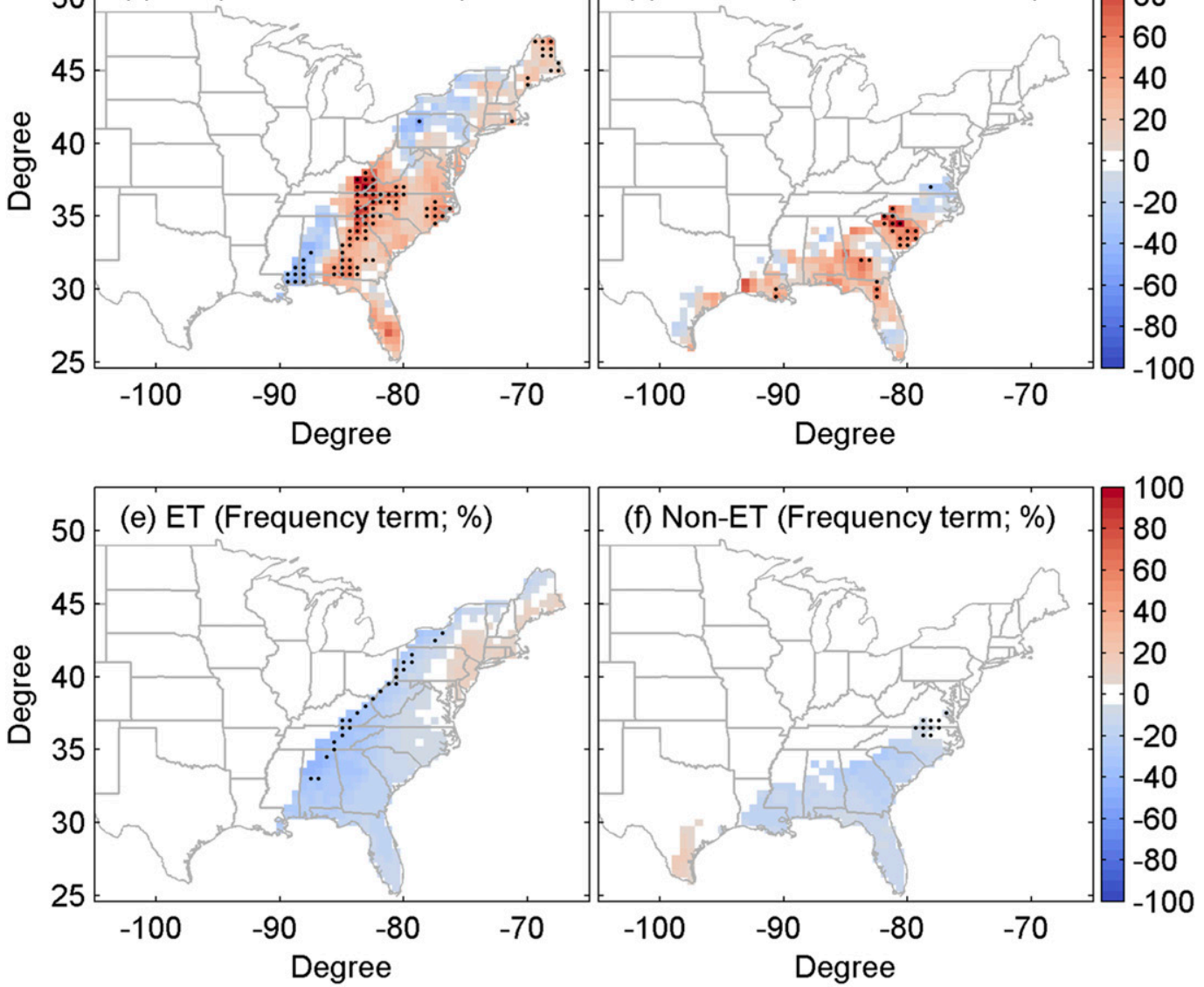

FIG. 8. (a) Projected change in July-November ET-storm rainfall between the PD and GW runs. The contribution of (c) the storm rain-rate term and (e) the frequency term to the change of rainfall for ET storms. (b),(d),(f) As in (a),(c),(e), but for non-ET-storm rainfall. Regions with storm rainfall in the PD run lower than $5 \mathrm{~mm} \mathrm{yr}^{-1}$ are masked.

rain rate. Although there are few regions with significant changes for storm frequency and rain rate in the northeastern United States, positive contribution from the two terms leads to significant increase of ET-storm rainfall along the coastal line (Figs. 8a,c,e).
As seen in Figs. 8d and 8f, the impact of non-ET-storm rainfall is concentrated in the southeastern United States. Compared to the contribution from both storm rain rate and frequency, the change of storm rainfall shows more spatial heterogeneity, highlighting the 

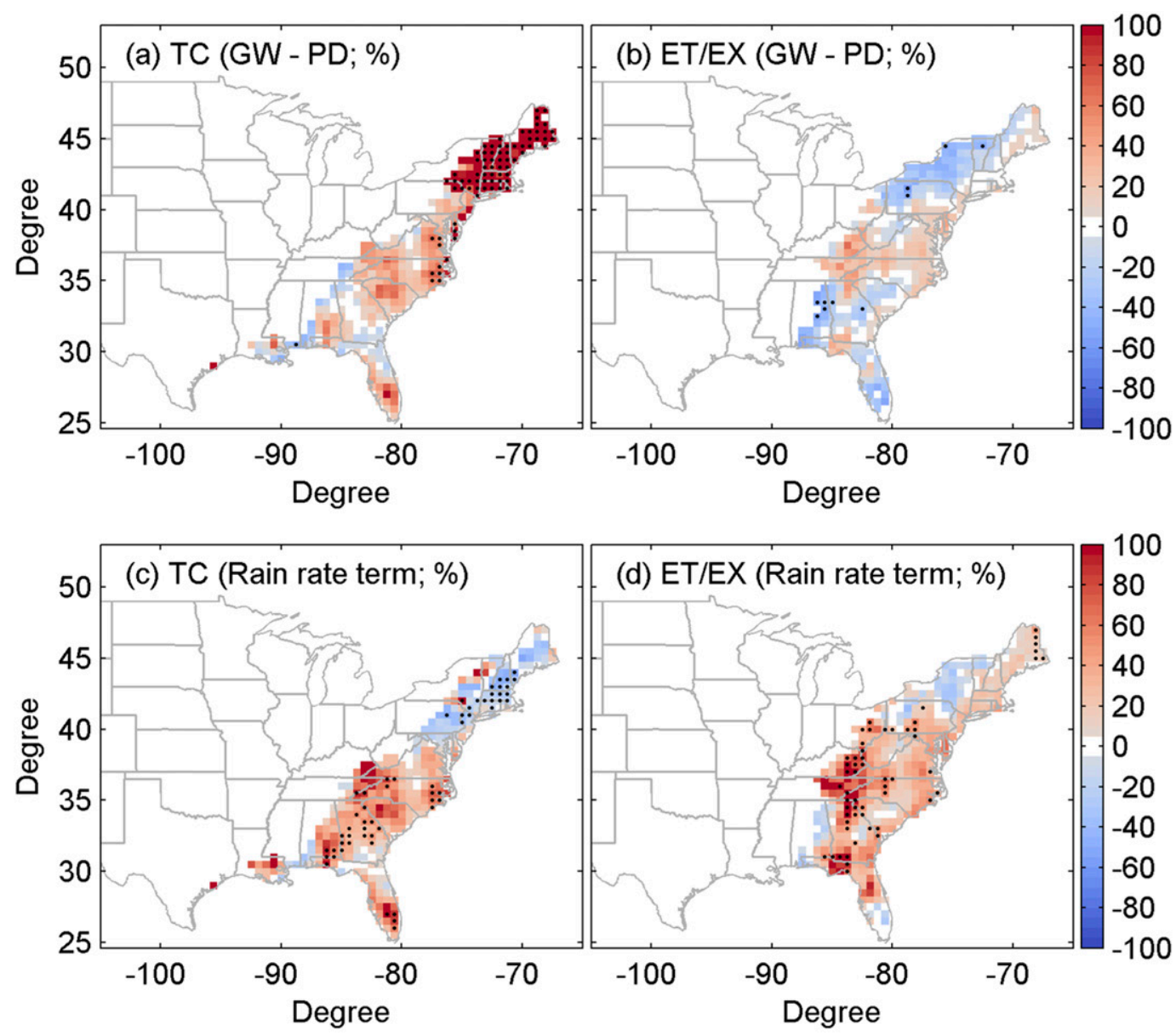

(d) ET/EX (Rain rate term; \%)
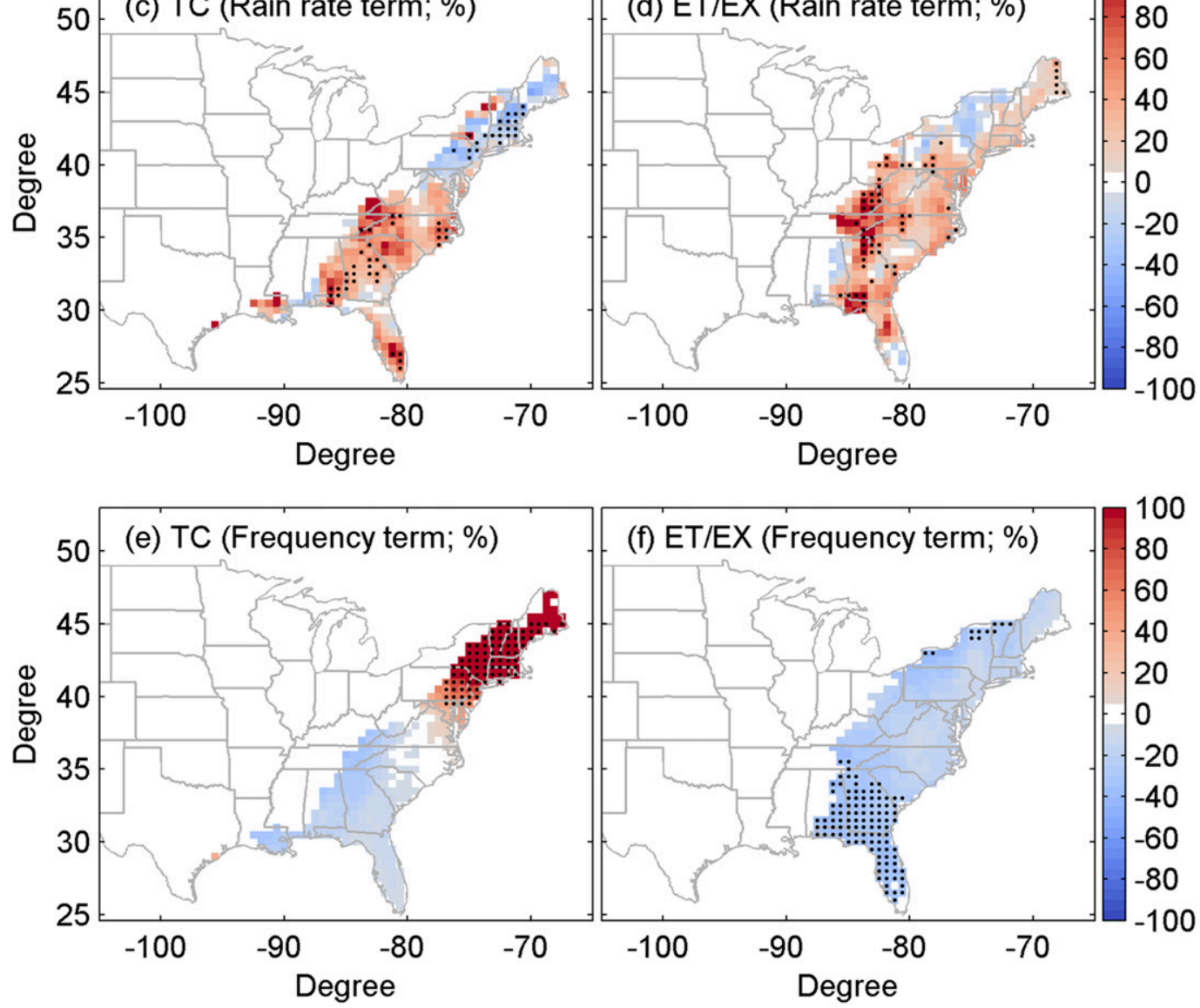

FIG. 9. (a) Projected change in July-November TC-phase rainfall for ET storms between the PD and GW runs. The contribution of (c) the storm rain-rate term and (e) the frequency term to the change of the TC-phase rainfall for ET storms. (b),(d),(f) As in (a),(c),(e), but for the ET/EX phase. Regions with storm rainfall in the PD run lower than $2.5 \mathrm{~mm} \mathrm{yr}^{-1}$ are masked.

competition between higher storm rain rates and lower storm frequency (Figs. 8d,f).

We examine the projected change of July-November ET-storm rainfall for the TC and ET/EX phases, respectively (Fig. 9). We first focus on the southeastern United States. For the two phases, the storm rain rate has positive contributions to the change of rainfall in most regions (Figs. 9c,d). In contrast, we find negative 
contributions from the storm frequency (Figs. 9e,f). Another prominent feature is that, because of the projected decrease of storm frequency, there are few regions with significant increase of rainfall in spite of significantly increased storm rain rate in large areas. FLOR projects a significant decrease of storm frequency for the ET/EX phase in Florida and Georgia, in striking contrast with the pronounced increase of TC-phase frequency in New England areas; that is, there is a poleward shift of the TC stages of storms at landfall. This feature will be discussed in more detail later. The rainfall change in the northeastern United States shows large differences between the two phases (Figs. 9a,b). The projected increase of storm rainfall for the TC phase reaches a magnitude of about $100 \%$ or higher, while the rainfall for the ET/EX phase shows a decrease or little change (Figs. 9a,b). The contrast of rainfall change for the two phases highlights the dominant role of the TC phase in the increased ET-storm rainfall in the northeastern United States (Fig. 8a). Because of the projected decrease of rain rate (Fig. 9c), the rainfall increase for the TC phase is dominated by the pronounced increase of storm frequency in the northeastern United States (Fig. 9e). Liu et al. (2017) reported increased sea surface temperature and decreased vertical wind shear in the midlatitudes in a warming climate. It is hypothesized that, under global warming, climate conditions are more conducive to maintaining storms in the tropical phase, even at relatively high latitudes (e.g., New England). Consistent with this hypothesis, the latitude of ET onset for storms passing through New England, New Jersey, Pennsylvania, and New York, as the climate warms, shifts poleward approximately $1.7^{\circ}$ latitude with a significance level $p<0.01$ (Fig. 10). This significant poleward shift still holds in terms of all landfalling-ET storms, consistent with the significant decrease of storm frequency for the ET/EX phase in Florida and Georgia (Fig. 9f). However, the striking increase of TC-phase storm frequency and rainfall resulting from the poleward shift of ET onset in New England, New York, and Pennsylvania is not seen in other states where the projected decrease of storm frequency caused by fewer landfalling storms plays a dominant role (see Figs. 6d and 9e). The changing properties of the partition of landfalling-storm frequency between the TC and ET/EX phases may have important implications for threats from wind and storm surge in addition to rainfall and resultant flooding hazards.

Compared to the TC phase, the attribution analyses find opposite results for the ET/EX phase in the northeastern United States. The increased storm rain rate is

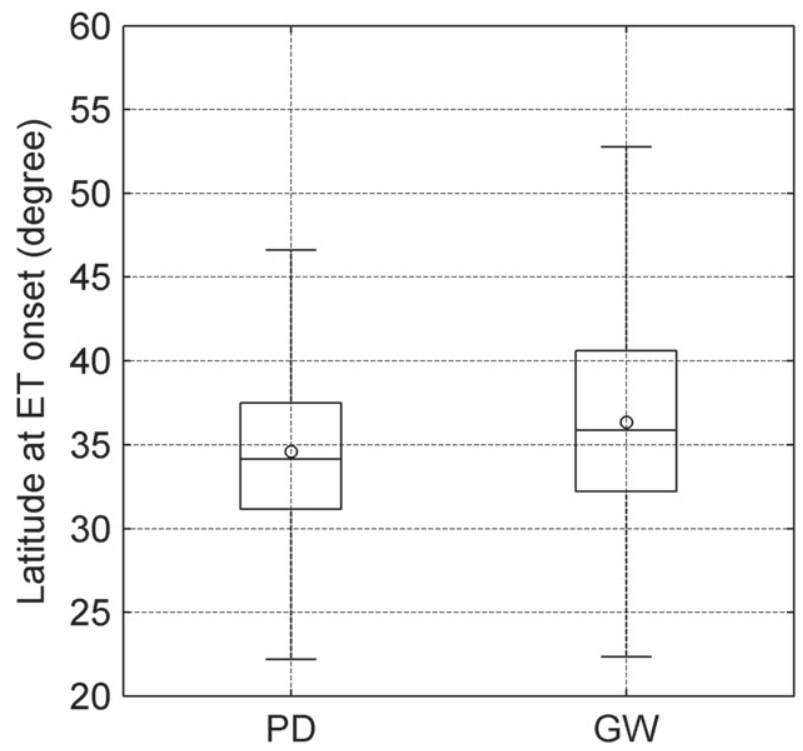

FIG. 10. Box-and-whisker plots of the latitude $\left({ }^{\circ} \mathrm{N}\right)$ at ET onset for the PD and GW runs for storms passing through New England, New Jersey, Pennsylvania, and New York. The limits of whiskers represent the 10th and 90th percentiles. The limits of boxes represent the 25 th and 75 th percentiles. The line inside the boxes and the circle indicate median and mean, respectively. The change of latitude between PD and GW runs is statistically significant $(p<$ 0.01 ) based on the two-sided Mann-Whitney-Wilcoxon median test.

dominated by decreased storm frequency, leading to an overall decrease of July-November storm total rainfall (Figs. 9b,d,f). The increased storm rain rates, however, imply increased flood risk for individual ET/EX-phase storms in the northeastern United States.

We examine the projected change of average stormcentered landfalling-storm rainfall composite for the TC phase and ET/EX phase, respectively (Fig. 11). For the TC phase, the change of composite rainfall in terms of rain intensity has two peaks in the right quadrant (Fig. 11e). The peak in the front-right quadrant highlights the impact of frictional effects because for the ocean only the peak in the rear-right quadrant near the eyewall is seen (not shown). The other peak is roughly in the eyewall regions. In contrast, the composite rainfall shows the largest fractional increase in areas far from the storm center with statistical significance (Fig. 11g), broadly consistent with previous work (Wright et al. 2015). However, the storm rainfall total does not show a substantial increase (Figs. 11a,c), similar to that over ocean and in agreement with the results in Lin et al. (2015). In contrast with the TC phase, the increase of rainfall composite for the ET/EX phase is concentrated in the front-left quadrant (Figs. 11f,h). Similar to the TC phase, for the ET/EX phase we observe significant 
(a) TC (PD; mm day $\left.{ }^{-1}\right)$

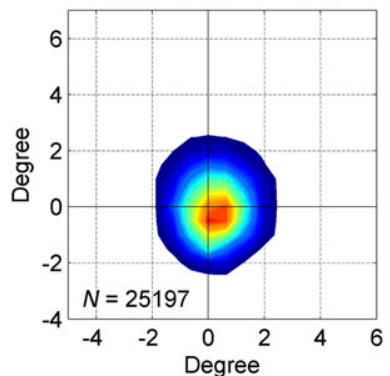

(e) TC (GW - PD; mm day ${ }^{-1}$ )

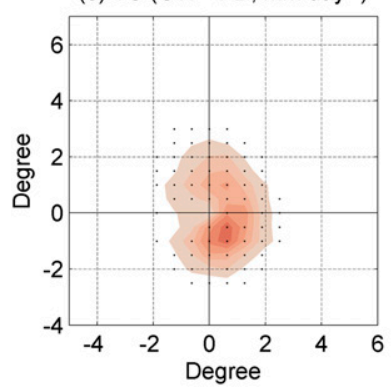

(b) ET/EX (PD; mm day ${ }^{-1}$ )

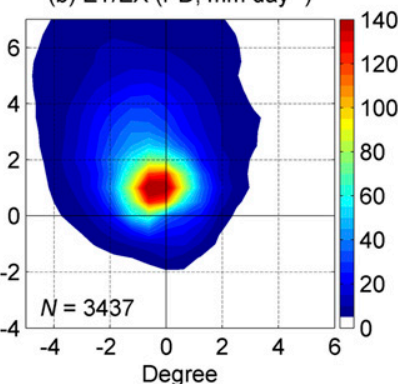

(f) ET/EX (GW - PD; mm day $\left.{ }^{-1}\right)$

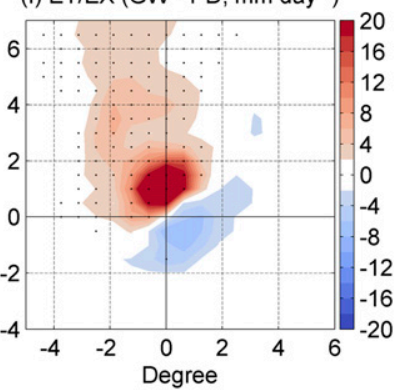

(c) TC (GW; mm day ${ }^{-1}$ )

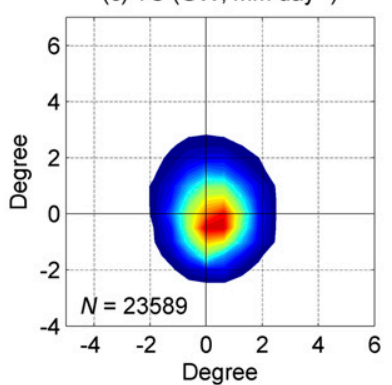

(g) TC (GW - PD; \%)

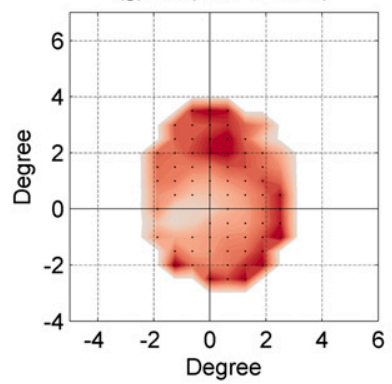

(d) ET/EX (GW; mm day ${ }^{-1}$ )

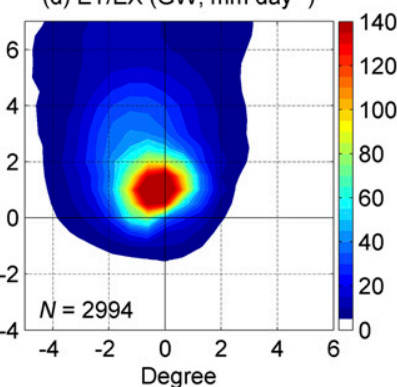

(h) ET/EX (GW - PD; \%)

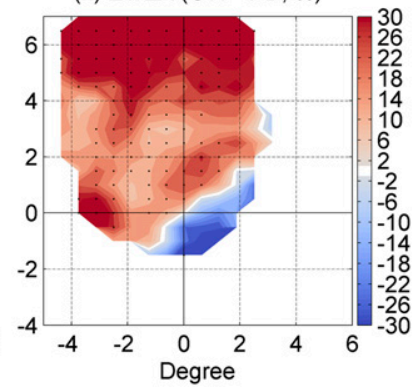

FIG. 11. As in Fig. 5, but for the PD and GW runs. Average storm-centered rainfall composite for the (a) PD and (c) GW runs for the TC phase, and (e),(g) the change in the rain-rate composite between the PD and GW runs. (b),(d),(f),(h) As in (a),(c),(e),(g), but for the ET/EX phase. Regions with storm rainfall lower than $5 \mathrm{~mm}_{\text {day }}{ }^{-1}$ are masked.

fractional increase over regions far from the storm center in a warming climate (Fig. 11h).

The contribution of pronounced outerband rainfall increase to the change of the spatial rainfall pattern is explored by repeating the analyses using a storm size of $600 \mathrm{~km}$. The change of storm size from 500 to $600 \mathrm{~km}$ does not lead to a significant difference in the change of geographic rainfall pattern (figure not shown), probably as a result of the lower rainfall magnitude in outer bands relative to inner-core regions. We examine the comparison between the rainfall change for the TC and ET/EX phases and the Clausius-Clapeyron scaling represented by SST changes over the area $10^{\circ}-30^{\circ} \mathrm{N}$, $20^{\circ}-80^{\circ} \mathrm{W}$. The Clausius-Clapeyron relation indicates that the atmospheric specific humidity increases by approximately $7 \%{ }^{\circ} \mathrm{C}^{-1}$ increase in SST given that the relative humidity has negligible change. The fractional increase of landfalling-storm rainfall for the TC phase grows with increased averaging radius (Fig. 12) and is larger than the Clausius-Clapeyron scaling at large radius.

Over ocean, TC-phase rainfall tends to be more conducive to SST increase and shows a larger increase than over land (Fig. 12). The rainfall increase for the TC phase over both land and ocean exceeds the Clausius-Clapeyron scaling at large averaging radius, suggesting the role of dynamical effects in addition to enhanced water vapor convergence as a result of increased vapor holding capacity. This is consistent with increased storm intensity with statistical significance $(p<0.01)$ in terms of maximum 10-m wind. For the ET/EX phase, the change of rainfall in the front-left quadrant with respect to the radius shows a similar trend to the TC phase. Over land, the rainfall increase surpasses the scaling at a radius larger than $100 \mathrm{~km}$, and this radius increases to about $200 \mathrm{~km}$ over ocean. These results suggest that, in addition to increased water vapor, an enhanced large-scale ascent associated with ET may

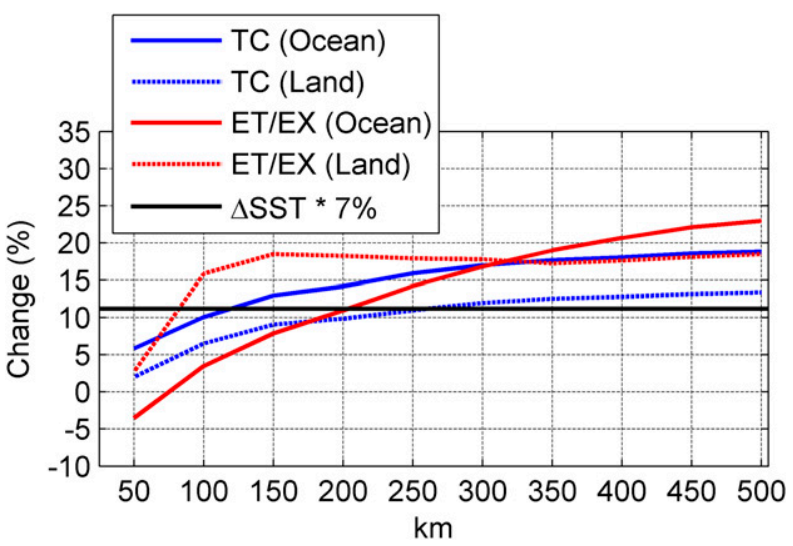

FIG. 12. The change (\%) of rainfall for the TC phase and ET/EX phase with respect to the averaging radius from the storm center. For the ET/EX phase, only the front-left quadrant relative to the storm center is presented. 
contribute to the pronounced increase of rainfall for the ET/EX phase.

\section{Summary}

We examine the frequency of landfalling tropical cyclones and associated rainfall in the United States with the GFDL FLOR coupled climate model. We compare the FLOR results against observed tracks and rainfall for the July-November 1979-2005 seasons. We examine the change of storm frequency and rainfall through comparisons between the future climate projection under the RCP4.5 scenario over 2056-2100 and the presentday simulations over 1961-2005. For the first time, we examine the role of extratropical transition in the landfalling-TC rainfall and its projection under anthropogenic warming. The main conclusions are summarized as follows:

1) FLOR shows substantial skill in simulating the geographic distribution of landfalling-TC frequency but underestimates rainfall magnitudes. This negative bias may be attributable to the imperfect simulation of the spatial pattern of the landfalling-TC genesis and the impact of large-scale climate indices (e.g., SNAO) on landfall ratio. FLOR accurately simulates the spatial pattern of landfalling-TC rainfall observed in NLDAS but shows negative bias.

2) Compared to NLDAS, FLOR exhibits good skill in simulating the spatial variability of annual storm rainfall for landfalling-ET and landfalling-non-ET events in spite of underestimation of the rainfall amount. Rainfall from ET storms covers a much larger area than non-ET storms and plays a more prominent role in the eastern coastal states. For ET storms, the striking spatial contrast of rainfall for the TC and ET/EX phases is accurately simulated by FLOR, as illustrated through comparisons against NLDAS.

3) For the TC phase, the storm-centered rainfall composite analyses show that FLOR produces higher rain rates in the inner core than NLDAS and does not accurately reproduce the concentration of rainfall in the front quadrants in NLDAS. However, FLOR shows good skill in simulating the concentration of rainfall in the front-left quadrant in the ET/EX phase.

4) Under the RCP4.5 scenario, FLOR projects significant decreases of landfalling-TC frequency in much of the southeastern United States, consistent with the results in Wright et al. (2015). Compared to landfalling-TC frequency, the change of TC rainfall in the southern United States exhibits larger spatial heterogeneity and statistical significance in fewer regions caused by the competition between decreased storm frequency and increased storm rain rate. The change of TC rainfall in the northeastern United States gradually shifts from increase to decrease as one moves inland from the coastal lines, consistent with the change of storm frequency.

5) The change of ET-storm rainfall exhibits a similar spatial pattern to the TC rainfall. The difference is that ET storms have larger areas with a statistically significant increase of rainfall in the northeastern coastal regions. In most regions of the southeastern United States, except Alabama, FLOR projects a complex changing pattern for ET-storm rainfall caused by the compensations between increased storm rain rate (with statistical significance in the southern Appalachian Mountains) and decreased storm frequency. This holds true for rainfall change of non-ET storms and storms in TC and ET/EX phases. In the northeastern United States, the most prominent feature is the increase of TC-phase storm frequency and associated rainfall, consistent with the significant poleward shift of ET location for storms passing through New England, New Jersey, Pennsylvania, and New York as climate warms. It is hypothesized that the increased SST and decreased wind shear provide a more favorable future climate to maintaining storms in the tropical phase at relatively high latitudes.

6) The analyses of storm-centered rainfall composites show a statistically significant increase of storm rain rates for both the TC phase and ET/EX phase. For the two phases, the greatest fractional increase occurs far from the storm center (Wright et al. 2015). The fractional change of TC-phase rainfall increases with respect to averaging radius and becomes larger than the Clausius-Clapeyron scaling at large radius, broadly consistent with results in Wright et al. (2015). This is also found in the frontleft quadrant of ET/EX-phase storms.

In this study, we explore the ability of the GFDL FLOR climate model to simulate and project the landfalling-TC frequency and associated rainfall in the United States. A distinction of this study from previous work is the examination of the role of ET. A surprising finding is the increased frequency of TC-phase storms in the northeastern United States, a key element of the increased rainfall. Furthermore, the increase of landfalling-storm frequency with tropical characteristics may have important implications for changes of wind and storm surge hazards in the future and needs more investigation in the future work. 
The shortcoming of FLOR for simulating landfallingTC rainfall suggests the need to explore simulations from multiple models for more robust projections. For example, the higher atmospheric resolution version of FLOR (HiFLOR) has shown improved simulation and prediction of major hurricanes as well as the teleconnection between TCs and modes of climate variability (e.g., El Niño-Southern Oscillation) than FLOR (Murakami et al. 2015, 2016b; Zhang et al. 2016b). In addition, the use of higher land resolution is expected to produce better simulations of the influence of landfall on TC rainfall compared to the moderate resolution version of FLOR. Future studies will use HiFLOR to study the responses of landfalling-TC rainfall to global warming and compare the results to those from FLOR.

Acknowledgments. This work was supported in part by Award NA14OAR4830101 from the National Oceanic and Atmospheric Administration, U.S. Department of Commerce, and the National Science Foundation (Grants EAR1520683 and AGS-1262099). The HURDAT2 best track data are obtained from the National Hurricane Center (https:/www.nhc.noaa.gov/data/hurdat/hurdat2-1851-2017050118.txt). The CFSR data are obtained from the Research Data Archive at the National Center for Atmospheric Research (https://rda.ucar.edu/). The climate model used in this study is GFDL FLOR with code available at the NOAA/GFDL website (https://www.gfdl.noaa.gov/cm2-5and-flor/). We want to thank the two anonymous reviewers for their comments that improved the quality of this paper.

\section{REFERENCES}

Atallah, E. H., and L. F. Bosart, 2003: The extratropical transition and precipitation distribution of Hurricane Floyd (1999). Mon. Wea. Rev., 131, 1063-1081, https://doi.org/10.1175/ 1520-0493(2003)131<1063:TETAPD>2.0.CO;2.

,-- , and A. R. Aiyyer, 2007: Precipitation distribution associated with landfalling tropical cyclones over the eastern United States. Mon. Wea. Rev., 135, 2185-2206, https:// doi.org/10.1175/MWR3382.1.

Barlow, M., 2011: Influence of hurricane-related activity on North American extreme precipitation. Geophys. Res. Lett., 38, L04705, https://doi.org/10.1029/2010GL046258.

Chavas, D. R., and K. A. Emanuel, 2010: A QuikSCAT climatology of tropical cyclone size. Geophys. Res. Lett., 37, L18816, https://doi.org/10.1029/2010GL044558.

— E. Yonekura, C. Karamperidou, N. Cavanaugh, and K. Serafin, 2013: U.S. hurricanes and economic damage: Extreme value perspective. Nat. Hazards Rev., 14, 237-246, https://doi.org/10.1061/(ASCE)NH.1527-6996.0000102.

Chen, B.-F., R. L. Elsberry, and C.-S. Lee, 2014: Origin and maintenance of the long-lasting, outer mesoscale convective system in Typhoon Fengshen (2008). Mon. Wea. Rev., 142, 2838-2859, https://doi.org/10.1175/MWR-D-14-00036.1.

Colle, B. A., 2003: Numerical simulations of the extratropical transition of Floyd (1999): Structural evolution and responsible mechanisms for the heavy rainfall over the northeast United States. Mon. Wea. Rev., 131, 2905-2926, https://doi.org/ 10.1175/1520-0493(2003)131<2905:NSOTET>2.0.CO;2.

Czajkowski, J., K. Simmons, and D. Sutter, 2011: An analysis of coastal and inland fatalities in landfalling US hurricanes. Nat. Hazards, 59, 1513-1531, https://doi.org/10.1007/ s11069-011-9849-x.

, G. Villarini, E. Michel-Kerjan, and J. A. Smith, 2013: Determining tropical cyclone inland flooding loss on a large scale through a new flood peak ratio-based methodology. Environ. Res. Lett., 8, 044056, https://doi.org/10.1088/ 1748-9326/8/4/044056.

Delworth, T. L., and Coauthors, 2006: GFDL's CM2 global coupled climate models. Part I: Formulation and simulation characteristics. J. Climate, 19, 643-674, https://doi.org/10.1175/ JCLI3629.1.

- and Coauthors, 2012: Simulated climate and climate change in the GFDL CM2.5 high-resolution coupled climate model. J. Climate, 25, 2755-2781, https://doi.org/10.1175/JCLI-D-11-00316.1.

DiMego, G. J., and L. F. Bosart, 1982: The transformation of tropical storm Agnes into an extratropical cyclone. Part I: The observed fields and vertical motion computations. Mon. Wea. Rev., 110, 385-411, https://doi.org/10.1175/ 1520-0493(1982)110<0385:TTOTSA $>2.0 . C O ; 2$.

Evans, J. L., and R. E. Hart, 2003: Objective indicators of the life cycle evolution of extratropical transition for Atlantic tropical cyclones. Mon. Wea. Rev., 131, 909-925, https://doi.org/10.1175/ 1520-0493(2003)131<0909:OIOTLC >2.0.CO;2.

Harris, L. M., S.-J. Lin, and C. Tu, 2016: High-resolution climate simulations using GFDL HiRAM with a stretched global grid. J. Climate, 29, 4293-4314, https://doi.org/10.1175/ JCLI-D-15-0389.1.

Hart, R. E., 2003: A cyclone phase space derived from thermal wind and thermal asymmetry. Mon. Wea. Rev., 131, 585-616, https://doi.org/10.1175/1520-0493(2003)131<0585: ACPSDF $>2.0 . \mathrm{CO} ; 2$.

— and J. L. Evans, 2001: A climatology of the extratropical transition of Atlantic tropical cyclones. J. Climate, 14, 546-564, https:// doi.org/10.1175/1520-0442(2001)014<0546:ACOTET>2.0.CO;2.

Jia, L., and Coauthors, 2015: Improved seasonal prediction of temperature and precipitation over land in a high-resolution GFDL climate model. J. Climate, 28, 2044-2062, https:// doi.org/10.1175/JCLI-D-14-00112.1.

Jiang, H., and E. J. Zipser, 2010: Contribution of tropical cyclones to the global precipitation from eight seasons of TRMM data: Regional, seasonal, and interannual variations. J. Climate, 23, 1526-1543, https://doi.org/10.1175/ 2009JCLI3303.1.

Khouakhi, A., G. Villarini, and G. A. Vecchi, 2017: Contribution of tropical cyclones to rainfall at the global scale. J. Climate, $\mathbf{3 0}$, 359-372, https://doi.org/10.1175/JCLI-D-16-0298.1.

Kitabatake, N., 2011: Climatology of extratropical transition of tropical cyclones in the western North Pacific defined by using cyclone phase space. J. Meteor. Soc. Japan, 89, 309-325, https://doi.org/10.2151/jmsj.2011-402.

Knutson, T. R., J. J. Sirutis, S. T. Garner, G. A. Vecchi, and I. M. Held, 2008: Simulated reduction in Atlantic hurricane frequency under twenty-first-century warming conditions. Nat. Geosci., 1, 359-364, https://doi.org/10.1038/ngeo202.

_ and Coauthors, 2010: Tropical cyclones and climate change. Nat. Geosci., 3, 157-163, https://doi.org/10.1038/ngeo779.

- and Coauthors, 2013: Dynamical downscaling projections of twenty-first-century Atlantic hurricane activity: CMIP3 
and CMIP5 model-based scenarios. J. Climate, 26, 6591-6617, https://doi.org/10.1175/JCLI-D-12-00539.1.

—_ and Coauthors, 2015: Global projections of intense tropical cyclone activity for the late twenty-first century from dynamical downscaling of CMIP5/RCP4.5 scenarios. J. Climate, 28, 7203-7224, https://doi.org/10.1175/jcli-d-15-0129.1.

Kunkel, K. E., D. R. Easterling, D. A. R. Kristovich, B. Gleason, L. Stoecker, and R. Smith, 2010: Recent increases in U.S. heavy precipitation associated with tropical cyclones. Geophys. Res. Lett., 37, L24706, https://doi.org/ 10.1029/2010GL045164.

Landsea, C. W., and J. L. Franklin, 2013: Atlantic hurricane database uncertainty and presentation of a new database format Mon. Wea. Rev., 141, 3576-3592, https://doi.org/10.1175/ MWR-D-12-00254.1.

Lin, N., J. A. Smith, G. Villarini, T. P. Marchok, and M. L. Baeck, 2010: Modeling extreme rainfall, winds, and surge from Hurricane Isabel (2003). Wea. Forecasting, 25, 1342-1361, https://doi.org/10.1175/2010WAF2222349.1.

Lin, Y., M. Zhao, and M. Zhang, 2015: Tropical cyclone rainfall area controlled by relative sea surface temperature. Nat. Commun., 6, 6591, https://doi.org/10.1038/ncomms7591.

_ , and K. E. Mitchell, 2005: The NCEP Stage II/IV hourly precipitation analyses: Development and applications. 19th Conf. on Hydrology, San Diego, CA, Amer. Meteor. Soc., 1.2, https://ams.confex.com/ams/pdfpapers/83847.pdf.

Liu, M., and J. A. Smith, 2016: Extreme rainfall from landfalling tropical cyclones in the eastern United States: Hurricane Irene (2011). J. Hydrometeor., 17, 2883-2904, https://doi.org/10.1175/ JHM-D-16-0072.1.

— , G. A. Vecchi, J. A. Smith, and H. Murakami, 2017: The present-day simulation and twenty-first-century projection of the climatology of extratropical transition in the North Atlantic. J. Climate, 30, 2739-2756, https://doi.org/10.1175/JCLI-D-16-0352.1.

Lyons, S. W., 2004: U.S. tropical cyclone landfall variability: 19502002. Wea. Forecasting, 19, 473-480, https://doi.org/10.1175/ 1520-0434(2004)019<0473:UTCLV>2.0.CO;2.

McAdie, C. J., C. W. Landsea, C. J. Neumann, J. E. David, E. S Blake, and G. R. Hammer, 2009: Tropical cyclones of the North Atlantic Ocean, 1851-2006 (with 2007 and 2008 track maps included). NOAA/NWS/NESDIS Historical Climatological Series Rep. 6-2, 238 pp., http://purl.access.gpo.gov/ GPO/LPS119129.

Mitchell, K. E., and Coauthors, 2004: The multi-institution North American Land Data Assimilation System (NLDAS): Utilizing multiple GCIP products and partners in a continental distributed hydrological modeling system. J. Geophys. Res. 109, D07S90, https://doi.org/10.1029/2003JD003823.

Murakami, H., and Coauthors, 2015: Simulation and prediction of category 4 and 5 hurricanes in the high-resolution GFDL HiFLOR coupled climate model. J. Climate, 28, 9058-9079, https://doi.org/10.1175/JCLI-D-15-0216.1.

_, G. Villarini, G. A. Vecchi, W. Zhang, and R. Gudgel, 2016a: Statistical-dynamical seasonal forecast of North Atlantic and U.S. landfalling tropical cyclones using the high-resolution GFDL FLOR coupled model. Mon. Wea. Rev., 144, 21012123, https://doi.org/10.1175/MWR-D-15-0308.1.

— and landfalling tropical cyclones using a high-resolution GFDL coupled climate model. J. Climate, 29, 7977-7989, https://doi.org/10.1175/JCLI-D-16-0233.1.

Prat, O. P., and B. R. Nelson, 2013: Mapping the world's tropical cyclone rainfall contribution over land using the
TRMM Multi-satellite Precipitation Analysis. Water Resour. Res., 49, 7236-7254, https://doi.org/10.1002/ wrcr.20527.

Rappaport, E. N., 2000: Loss of life in the United States associated with recent Atlantic tropical cyclones. Bull. Amer. Meteor. Soc., 81, 2065-2073, https://doi.org/10.1175/1520-0477(2000)081<2065: LOLITU > 2.3.CO;2.

, 2014: Fatalities in the United States from Atlantic tropical cyclones: New data and interpretation. Bull. Amer. Meteor. Soc., 95, 341-346, https://doi.org/10.1175/ BAMS-D-12-00074.1.

Saha, S., and Coauthors, 2010: The NCEP Climate Forecast System Reanalysis. Bull. Amer. Meteor. Soc., 91, 1015-1057, https:// doi.org/10.1175/2010BAMS3001.1.

Scoccimarro, E., S. Gualdi, G. Villarini, G. A. Vecchi, M. Zhao, K. Walsh, and A. Navarra, 2014: Intense precipitation events associated with landfalling tropical cyclones in response to a warmer climate and increased $\mathrm{CO}_{2}$. J. Climate, 27, 4642-4654, https://doi.org/10.1175/JCLI-D-14-00065.1.

Smith, J. A., G. Villarini, and M. L. Baeck, 2011: Mixture distributions and the hydroclimatology of extreme rainfall and flooding in the eastern United States. J. Hydrometeor., 12, 294-309, https://doi.org/10.1175/2010JHM1242.1.

Sturdevant-Rees, P., J. A. Smith, J. Morrison, and M. L. Baeck, 2001: Tropical storms and the flood hydrology of the central Appalachians. Water Resour. Res., 37, 2143-2168, https:// doi.org/10.1029/2000WR900310.

Vecchi, G. A., and Coauthors, 2014: On the seasonal forecasting of regional tropical cyclone activity. J. Climate, 27, 7994-8016, https://doi.org/10.1175/JCLI-D-14-00158.1.

Villarini, G., and J. A. Smith, 2010: Flood peak distributions for the eastern United States. Water Resour. Res., 46, W06504, https:// doi.org/10.1029/2009WR008395.

_ - - M. L. Baeck, T. Marchok, and G. A. Vecchi, 2011: Characterization of rainfall distribution and flooding associated with U.S. landfalling tropical cyclones: Analyses of Hurricanes Frances, Ivan, and Jeanne (2004). J. Geophys. Res., 116, D23116, https://doi.org/10.1029/ 2011JD016175.

, D. A. Lavers, E. Scoccimarro, M. Zhao, M. F. Wehner, G. A. Vecchi, T. R. Knutson, and K. A. Reed, 2014a: Sensitivity of tropical cyclone rainfall to idealized global-scale forcings. J. Climate, 27, 4622-4641, https://doi.org/10.1175/ JCLI-D-13-00780.1.

, R. Goska, J. A. Smith, and G. A. Vecchi, 2014b: North Atlantic tropical cyclones and U.S. flooding. Bull. Amer. Meteor. Soc., 95, 1381-1388, https://doi.org/10.1175/BAMS-D-13-00060.1.

Willoughby, H. E., 2012: Distributions and trends of death and destruction from hurricanes in the United States, 19002008. Nat. Hazards Rev., 13, 57-64, https://doi.org/10.1061/ (ASCE)NH.1527-6996.0000046.

Wood, K. M., and E. A. Ritchie, 2014: A 40-year climatology of extratropical transition in the eastern North $\mathrm{Pa}$ cific. J. Climate, 27, 5999-6015, https://doi.org/10.1175/ JCLI-D-13-00645.1.

Wright, D. B., J. A. Smith, G. Villarini, and M. L. Baeck, 2013: Estimating the frequency of extreme rainfall using weather radar and stochastic storm transposition. J. Hydrol., 488, 150165, https://doi.org/10.1016/j.jhydrol.2013.03.003.

, -, and M. L. Baeck, 2014: Flood frequency analysis using radar rainfall fields and stochastic storm transposition. Water Resour. Res., 50, 1592-1615, https://doi.org/10.1002/ 2013WR014224. 
T. R. Knutson, and J. A. Smith, 2015: Regional climate model projections of rainfall from U.S. landfalling tropical cyclones. Climate Dyn., 45, 3365-3379, https://doi.org/10.1007/ s00382-015-2544-y.

Zhang, W., G. Villarini, G. A. Vecchi, H. Murakami, and R. Gudgel, 2016a: Statistical-dynamical seasonal forecast of western North Pacific and East Asia landfalling tropical cyclones using the high-resolution GFDL FLOR coupled model. J. Adv. Model. Earth Syst., 8, 538-565, https://doi.org/10.1002/ 2015 MS000607.
- and Coauthors, 2016b: Improved simulation of tropical cyclone responses to ENSO in the western North Pacific in the highresolution GFDL HiFLOR coupled climate model. J. Climate, 29, 1391-1415, https://doi.org/10.1175/JCLI-D-15-0475.1.

G. A. Vecchi, G. Villarini, H. Murakami, R. Gudgel, and X. Yang, 2017: Statistical-dynamical seasonal forecast of western North Pacific and East Asia landfalling tropical cyclones using the GFDL FLOR coupled climate model. J. Climate, 30, 2209-2232, https://doi.org/10.1175/ JCLI-D-16-0487.1. 